\title{
Hypertension Compendium
}

\section{Circulation Research Compendium on Hypertension}

The Epidemiology of Blood Pressure and Its Worldwide Management

Genetic and Molecular Aspects of Hypertension

Hypertension: Renin-Angiotensin-Aldosterone System Alterations

The Sympathetic Nervous System Alterations in Human Hypertension

Obesity-Induced Hypertension: Interaction of Neurohumoral and Renal Mechanisms

The Structural Factor of Hypertension: Large and Small Artery Alterations

Inflammation, Immunity, and Hypertensive End-Organ Damage

Clinical Value of Ambulatory Blood Pressure: Evidence and Limits

Sodium Intake and Cardiovascular Health

Randomized Controlled Trials of Blood Pressure Lowering in Hypertension: A Critical Reappraisal

New Approaches in the Treatment of Hypertension

Giuseppe Mancia, Guest Editor

\section{Randomized Controlled Trials of Blood Pressure Lowering in Hypertension}

A Critical Reappraisal

\author{
Alberto Zanchetti, Costas Thomopoulos, Gianfranco Parati
}

\begin{abstract}
Sixty-eight blood pressure (BP)-lowering randomized controlled trials (defined as randomized controlled trials comparing active treatment with placebo, or less active treatment, achieving a BP difference, performed between 1966 and end 2013 in cohorts with $\geq 40 \%$ hypertensive patients, and exclusive of trials in acute myocardial infarction, heart failure, acute stroke, and dialysis) were identified and meta-analyzed grouping the randomized controlled trials on the basis of clinically relevant questions: (1) does BP lowering reduce all types of cardiovascular outcome? (2) Is prevention of all outcomes proportional to the extent of systolic, diastolic, and pulse BP? (3) Have all classes of BP-lowering drugs been shown capable of reducing all types of cardiovascular outcome? (4) Is BP lowering beneficial when intervention is initiated at any grade (or stage) of hypertension? (5) Do BP-lowering randomized controlled trials provide evidence about systolic BP and diastolic BP targets of treatment? (6) Should BP-lowering treatment be preferentially addressed to patients in higher risk categories promising larger absolute treatment benefits? The results of these meta-analyses provide further support to current hypertension treatment guidelines by showing that BP lowering can significantly reduce major cardiovascular outcomes largely independent of the agents used, significant risk reduction is found at all hypertension grades (stages), and when systolic BP is lowered below a cut off of $140 \mathrm{~mm} \mathrm{Hg}$ with some further reduction limited to stroke at systolic BP values just $<130 \mathbf{~ m m ~ H g . ~ A b s o l u t e ~ r i s k ~ r e d u c t i o n ~ p r o g r e s s i v e l y ~ i n c r e a s e s ~ h i g h e r ~ i s ~ t o t a l ~ c a r d i o v a s c u l a r ~ r i s k , ~ b u t ~}$ this greater benefit is associated with a progressively higher residual risk, ie, higher treatment failures. (Circ Res. 2015;116:1058-1073. DOI: 10.1161/CIRCRESAHA.116.303641.)
\end{abstract}

Key Words: antihypertensive drugs $\boldsymbol{\square}$ cardiovascular death $\mathbf{~ c o r o n a r y ~ d i s e a s e ~} \boldsymbol{\square}$ heart failure - randomized controlled trial $\boldsymbol{\|}$ stroke

Original received November 25, 2014; revision received January 5, 2015; accepted January 9, 2015. In January 2015, the average time from submission to first decision for all original research papers submitted to Circulation Research was 14.7 days.

From the Istituto Auxologico Italiano, Milan, Italy (A.Z., G.P.); Centro Interuniversitario di Fisiologia Clinica e Ipertensione, University of Milan, Milan, Italy (A.Z.); Department of Cardiology, Helena Venizelou Hospital, Athens, Greece (C.T.); and Department of Health Sciences, University of MilanoBicocca, Milan, Italy (G.P.).

Correspondence to Alberto Zanchetti, MD, Direzione Scientifica, Istituto Auxologico Italiano, Via L. Ariosto 13, I-20145 Milano, Italy. E-mail alberto. zanchetti@auxologico.it

(C) 2015 American Heart Association, Inc. 


\begin{tabular}{|ll|}
\hline \multicolumn{2}{|l|}{ Nonstandard Abbreviations and Acronyms } \\
\hline BP & blood pressure \\
BPLTTC & Blood Pressure Lowering Trialists' Collaboration \\
CHD & coronary heart disease \\
DBP & diastolic blood pressure \\
HF & heart failure \\
PP & pulse pressure \\
RCT & randomized controlled trial \\
RR & risk ratio \\
SBP & systolic blood pressure \\
\hline
\end{tabular}

\section{Historical Perspective}

Therapy of hypertension was undoubtedly one of the major achievements of medicine during the second half of the 20th century. This is not only because pharmacological agents capable of reducing blood pressure (BP) have been successfully developed starting from the 1950s but also because, in the same time window, the effects of drug-induced BP lowering have rigorously been tested by means of the best evidence-providing approach, ie, through large randomized controlled trials (RCTs). Indeed, hypertension experts can be proud that antihypertensive therapy has been the first among cardiovascular therapies, several years before therapies of myocardial infarction and chronic heart failure (HF), that has been tested by this approach, using so-called hard end points, ie, outcomes that can be easily diagnosed and the diagnosis of which can be easily verified. ${ }^{1,2}$ The need of solid evidence in favor of therapeutic lowering of BP was particularly impelling because prejudice prevailing among clinicians and investigators until the mid 20th century was that "hypertension may be an important compensatory mechanism, which should not be tampered with, even were it certain we could control it." ${ }^{3}$ This prejudice was, so to say, a heritage of the old ontological concept of medicine, by which changes in body functions were simply compensatory mechanisms to preserve some other functions of the body: in the case of hypertension to preserve perfusion of vital organs, especially the kidney. Hence, the term essential by which arterial hypertension has long been baptized, as was fever in the 18th century, on the basis of the same ontological interpretation of its beneficial compensatory action: "la fièvre essentielle est une affection de la vie qui s'efforce d'éloigner la mort" (essential fever is an affection of life that endeavors to postpone death). ${ }^{4}$ Still in 1957, an author could write on the Lancet "Even in the case of true arterial hypertension neither product of test tube or crucible halts, nor delays materially, the unfavorable course of the disease." 5

When the first antihypertensive agents became available during the 1950s, they were tested on the most severe form of hypertension, malignant hypertension. These early studies were uncontrolled, and the benefits of BP lowering were established by a historical comparison of the lengthened survival of a cohort of treated patients with the bad survival of cohorts of patients followed-up in the previous years when effective drugs were not available. A study published in 1959 by Leishman ${ }^{6}$ showed that although $\approx 90 \%$ of treated patients had died within 5 years, among treated patients, 5 year-death was of $<30 \%$.
A subsequent study by Hamilton et $\mathrm{al}^{7}$ was the first controlled study, in which half of the patients were actively treated, whereas the other half was left untreated, but assignment was not randomized, namely patients were assigned alternatively to one or the other treatment. Nonetheless, this relatively small study (61 patients with initial systolic BP/ diastolic BP [SBP/DBP] values of $\approx 230 / 130 \mathrm{~mm} \mathrm{Hg}$ but no clinical signs of cardiovascular disease) produced some convincing evidence that $\mathrm{BP}$ lowering could significantly reduce the incidence of cardiovascular outcomes also in nonmalignant hypertension.

The first randomized trial was a small one by Wolff and Lindeman, ${ }^{8}$ immediately followed by a slightly larger one by the Veterans Administration Cooperative Study Group on antihypertensive agents, ${ }^{9}$ which included patients with markedly elevated DBP (115 through $129 \mathrm{~mm} \mathrm{Hg}$ ), but it was able to show that BP lowering by drugs could prevent as many as 24 morbid or mortal events for every 100 severely hypertensive patients treated for 1 year. Because this trial was terminated prematurely for ethical reasons, it could not provide evidence on the specific efficacy of drug therapy of severe hypertension on strokes and coronary events, respectively.

Between 1966 and 1992, 17 trials, including 47653 hypertensive patients, were completed, all comparing active BP-lowering drug treatment with placebo or, more rarely, no drug treatment or less active treatment, to answer the crucial question as to whether drug-induced BP lowering was indeed beneficial. ${ }^{2}$ These trials were meta-analyzed by Collins and MacMahon in $1994^{10}$ with the demonstration that BP lowering by drugs significantly reduced both strokes and coronary events, although the former more markedly and also significantly reduced cardiovascular mortality.

Most of the placebo-controlled trials in hypertension were initiated and conducted in the period from 1965 to 1985 , and therefore, the antihypertensive drugs used in the active treatment arm were those drugs widely used at that time, namely thiazide or thiazide-like diuretics, $\beta$-blockers, methyldopa, reserpine, and hydralazine. Starting from about 1980, however, new classes of antihypertensive agents became increasingly used, namely calcium antagonists, angiotensin-converting enzyme inhibitors, and angiotensin receptor blockers. It was important, therefore, to test whether BP lowering by these new drugs was also effective in reducing incidence of cardiovascular events. The real question at stake was whether the benefits of antihypertensive therapy exclusively resided in the lowering of elevated BP independently of the drugs used or whether some drug classes had some additional benefits independent of that related to BP lowering. ${ }^{1,2}$ The previous demonstration that BP lowering by diuretics, $\beta$-blockers, and other older drugs did reduce cardiovascular event incidence made it difficult to test the new agents with the traditional design of using an entirely untreated (placebo) control group, unless patients were selected in a clinical context yet unexplored (old age, previous cardiovascular outcomes, etc). A favorite design was that of adding either the new agent or placebo on a background of preexisting antihypertensive therapy, although it must be recognized that a large number of these studies were not intended to investigate the effects of BP lowering but were 
rather searching for BP-independent benefits of some of the new agents.

Another large series of RCTs approached the problem of the effects of new antihypertensive agents by head-to-head comparison of new and traditional agents, and sometimes of agents belonging to 2 different new classes, with the assumption that, for similar BP reductions, similar or different incidences of cardiovascular events could indicate similarities or differences in the beneficial effects of the compared compounds. $^{2}$

Despite the large number of RCTs devoted to antihypertensive treatment, it must be recognized that several important issues of practical importance in the management of hypertension have not been investigated, or have rarely been investigated, or investigated according to diagnostic criteria or definitions hardly applicable today. ${ }^{11}$ Among these problems are the BP levels at which drug treatment should be initiated, the target BP levels to be aimed at by treatment, and whether either treatment initiation and target BP levels are influenced by assessment of total cardiovascular risk, with earlier and more intense treatment to be reserved to higher risk patients. ${ }^{11,12}$ The lack of definitive trial evidence on these issues is acknowledged in recent guidelines for the management of hypertension. ${ }^{13,14}$

\section{Critical Reappraisal of Available Evidence}

The large body of data provided by the numerous RCTs of antihypertensive drugs has been an obvious target of several meta-analyses, starting from the seminal one by Collins et al ${ }^{15}$ in 1990. Among available comprehensive meta-analyses of antihypertensive treatment RCTs, those of the Blood Pressure Lowering Trialists' Collaboration (BPLTTC) $)^{16-18}$ deliberately included only trials posterior to the time the BPLTTC protocol was prepared ${ }^{19}$ and preferentially considered those RCTs the individual data of which were available to the collaboration. The largest meta-analysis available until now is the one by Law et al, ${ }^{20}$ which included 147 trials published within 2007 but considered together trials testing antihypertensive agents in hypertension and under different clinical conditions, such as myocardial infarction, left ventricular dysfunction, and $\mathrm{HF}$, where drugs belonging to antihypertensive pharmaceutical classes were not administered with the intention of lowering BP, and their effects were probably independent of, or even hindered by, BP lowering. These important limitations of meta-analysis of Law et $\mathrm{al}^{20}$ have been appropriately underlined by Bangalore et al. ${ }^{21}$

Meta-analyses are known to have limitations being by definition post hoc analyses and being fraught with problems, the major one relating to criteria chosen for trial selection ${ }^{22}$ : loose criteria may introduce confounding factors from poorly designed or conducted trials, but tight criteria are likely to cause an even greater bias favoring preconceptions and expectations of the authors of meta-analysis., ${ }^{2,22}$ Although meta-analyses should not be considered the ultimate level of evidence, nonetheless, they are a powerful statistical method of estimating the average effect (and its confidence limits) of a given treatment, especially when the results of several RCTs are available. ${ }^{21}$ Furthermore, when structured around a relevant clinical question, they may provide a tentative answer to this question, with the caution that meta-analyses are hypothesis-generating instruments rather than a body of proof. ${ }^{22}$

With these considerations in mind, we have reviewed all RCTs of antihypertensive treatment performed from 1966 to the end of 2013 with the objective to provide some answers to the following major questions:

1. Does drug-induced BP lowering reduce incidence of all major types of fatal and nonfatal cardiovascular outcomes to a similar extent or are some types of cardiovascular events particularly susceptible to the beneficial effects of BP lowering?

2. Is prevention of all types of cardiovascular outcomes proportional to the extent of SBP, DBP, or pulse pressure $(\mathrm{PP})$ reduction?

3. Is there evidence available that BP lowering produced by drugs belonging to any of the major classes of antihypertensive agents is effective in reducing all or part of cardiovascular outcomes?

4. Do BP-lowering RCTs provide some evidence whether all grades (or stages) of hypertension are worth being treated with BP-lowering drugs, treatment being accompanied by significant relative and absolute reduction in the incidence of some major cardiovascular outcomes?

5. Do BP-lowering RCTs provide some evidence about the levels to which SBP or DBP should be brought by treatment so as to maximize outcome reduction?

6. Are relative and absolute reductions of the risk of different cardiovascular outcomes by BP-lowering treatment similar or different at different levels of baseline cardiovascular risk and should BP-lowering treatment be preferentially addressed to patients in risk categories promising larger absolute treatment benefits?

The above questions have been approached in a series of meta-analyses we have recently published in 4 separate articles. ${ }^{23-26}$ Their major results are here summarized and discussed together as an integrated critical reappraisal of the data provided by RCTs of BP-lowering treatment. The original articles should be consulted for methodological procedures and more detailed data presentation. Briefly, it can be mentioned that data from each RCT were weighted by patient numbers and follow-up duration. Risk ratios (RRs) and their $95 \%$ confidence intervals were calculated using the Mantel-Haenszel method and, when useful, standardized to a SBP/DBP difference of $10 / 5 \mathrm{~mm} \mathrm{Hg}$. A random-effects model was used for all analyses. Five-year absolute risk reductions of standardized BP lowering and the number of patients needed to treat for 5 years were also calculated.

\section{Effects of BP Lowering on Outcome Incidence in Hypertension}

A critical reappraisal of BP-lowering RCTs required first to establish clear criteria for defining this type of trials among the large number of those that tested drugs classified as antihypertensive. In our recent overview, ${ }^{23}$ we have defined as BP-lowering RCTs all those in which (1) any antihypertensive drugs were compared with placebo or no treatment with the intention to investigate the consequences of BP differences on cardiovascular outcomes or mortality or (2) a more intense BP-lowering treatment was compared with a less intense one with the intention to investigate outcome difference associated with BP difference. These 
trials were defined as intentional BP-lowering RCTs. To widen the body of evidence, we have also separately analyzed what we have defined nonintentional BP-lowering RCTs, ie, those trials in which BP-lowering drugs were compared with placebo and a between-group difference of $\geq 2 \mathrm{mmHg}$ in either SBP or DBP occurred, although the design of the trials was not that of investigating the effects of BP differences.

Furthermore, we have considered only RCTs in which BPlowering drugs were studied in cohorts of hypertensive patients, and, in a wider approach, in cohorts in which at least a consistent proportion of hypertensive patients were present (defined as $\geq 40 \%$ ). All trials in which drugs with BP-lowering properties were tested under conditions, such as myocardial infarction, HF, and acute stroke, and patients on dialysis were excluded. Further inclusion criteria were measurement of $\geq 1$ type of cardiovascular events as primary or secondary end point, BP values measured at baseline and during follow-up, $\geq 5$ events during follow-up, follow-up of $\geq 6$ months, and randomized allocation to treatment.

Literature search according to PRISMA (Preferred Reporting Items for Systematic Meta-Analyses) statement recommendations $^{27}$ led to the identification of 68 trials $^{8,9,28-96}$ with a total of 245855 participants followed-up for a mean of 4.3 years (1058177 patient-years). Forty-seven trials (153825 participants $)^{2,8,9,28-74}$ were of intentional BP lowering, and 21 (92060 participants) were classified as nonintentional BP-lowering trials ${ }^{75-96}$ (Table).

In the primary analysis, restricted to the 47 intentional BPlowering RCTs, all considered outcomes were significantly reduced by BP lowering, ${ }^{23}$ with the risk of stroke and HF being reduced to the greatest extent $(36 \%$ and $43 \%$, respectively, for a standardized SBP/DBP difference between active and

Table. Characteristics of All BP Lowering Treatment Trials Included

\begin{tabular}{|c|c|c|c|c|c|c|}
\hline Trial Acronym & $\begin{array}{l}\text { Patient } \\
\text { Number }\end{array}$ & Follow-Up, y & $\begin{array}{l}\text { Hypertensive } \\
\text { Patients, \% }\end{array}$ & $\begin{array}{c}\text { SBP/DBP } \\
\text { Difference, } \mathrm{mm} \text { Hg }\end{array}$ & $\begin{array}{c}\text { Baseline } \\
\text { BP-Lowering Drugs }\end{array}$ & $\begin{array}{l}\text { Quality Assessment } \\
\text { vScore }\end{array}$ \\
\hline \multicolumn{7}{|c|}{ Intentional, placebo (or no treatment) controlled trials } \\
\hline ACTION 28 & 7665 & 4.9 & $52 \%$ & $-5.4 /-3$ & Yes & $5 / 6$ \\
\hline ADVANCE $^{29}$ & 11140 & 4.3 & $>75 \%$ & $-5.6 /-4.2$ & Yes & $6 / 6$ \\
\hline $\begin{array}{l}\text { AUSTRALIAN- } \\
\text { Mild }^{30}\end{array}$ & 3427 & 4.0 & $100 \%$ & $\mathrm{NR} /-5.6$ & No & $5 / 6$ \\
\hline Barraclough $^{31}$ & 116 & 2.0 & $100 \%$ & $N R /-14.4$ & No & $4 / 6$ \\
\hline CAMELOT $T^{32}$ & 1991 & 2.0 & $60 \%$ & $-4.9 /-3.2$ & Yes & $4 / 6$ \\
\hline CARTER $^{33}$ & 99 & 4.0 & $100 \%$ & $-17 /-9$ & No & $4 / 6$ \\
\hline EWPHE $^{34}$ & 840 & 4.7 & $100 \%$ & $-21.7 /-8.3$ & No & $4 / 6$ \\
\hline \multicolumn{7}{|l|}{ FEVER } \\
\hline All ${ }^{35}$ & 9711 & 3.3 & $100 \%$ & $-4.7 /-2.3$ & Yes, low & $6 / 6$ \\
\hline$<153 \mathrm{~mm} \mathrm{Hg}{ }^{36}$ & 4855 & 3.3 & $100 \%$ & $-3.7 /-2.2$ & Yes, low & \\
\hline \multicolumn{7}{|l|}{ HDFP } \\
\hline$A \| l^{37}$ & 10940 & 5.0 & $100 \%$ & $-10 /-5.3$ & No & $5 / 6$ \\
\hline Stratum $90-94^{38}$ & 2043 & 5.0 & $100 \%$ & $-10 /-7$ & No & \\
\hline Stratum $1^{37,38}$ & 7825 & 5.0 & $100 \%$ & $-10 /-5$ & No & \\
\hline Stratum $2-3^{37}$ & 3115 & 5.0 & $100 \%$ & $-10 /-7$ & No & \\
\hline HEP 39 & 884 & 4.4 & $100 \%$ & $-18 /-11$ & No & $4 / 6$ \\
\hline $\mathrm{HSCSG}^{40}$ & 452 & 2.3 & $100 \%$ & $-15 /-12$ & No & $5 / 6$ \\
\hline Hunan province ${ }^{41}$ & 2080 & 4.7 & $100 \%$ & $-8.2 /-5.3$ & No & $3 / 6$ \\
\hline HYVET pilot ${ }^{42}$ & 1283 & 1.1 & $100 \%$ & $-22.2 /-10.9$ & No & $4 / 6$ \\
\hline HYVET $^{43}$ & 3845 & 2.1 & $100 \%$ & $-13.3 /-4.9$ & No & $5 / 6$ \\
\hline MRC-mild ${ }^{44}$ & 17354 & 5.0 & $100 \%$ & $-11.5 /-6$ & No & $4 / 6$ \\
\hline MRC-old 45 & 4396 & 5.8 & $100 \%$ & $-14 /-7.8$ & No & $4 / 6$ \\
\hline OSLO ${ }^{46}$ & 785 & 5 & $100 \%$ & $-16.7 /-9.8$ & No & $4 / 6$ \\
\hline PATS $^{47}$ & 5665 & 1.8 & $84 \%$ & $-5.3 /-3.4$ & No & $3 / 6$ \\
\hline PROGRESS ${ }^{48}$ & 6105 & 3.9 & $>48 \%$ & $-9 /-4$ & Yes & $5 / 6$ \\
\hline $\mathrm{SCOPE}^{49}$ & 4937 & 3.7 & $100 \%$ & $-3.3 /-1.7$ & Yes & $6 / 6$ \\
\hline SHEP pilot ${ }^{50}$ & 551 & 2.8 & $100 \%$ & $-16.9 /-3.9$ & No & $4 / 6$ \\
\hline SHEP51 & 4736 & 4.5 & $100 \%$ & $-13 /-3.9$ & No & $6 / 6$ \\
\hline Sprackling ${ }^{52}$ & 120 & 5.0 & $100 \%$ & $-16.5 /-4.3$ & No & $2 / 6$ \\
\hline STOP53 & 1627 & 2.1 & $100 \%$ & $-22.3 /-9.5$ & No & $5 / 6$ \\
\hline SystChina ${ }^{54}$ & 2394 & 3.0 & $100 \%$ & $-7.8 /-4$ & No & $4 / 6$ \\
\hline SystEur ${ }^{55}$ & 4695 & 2.6 & $100 \%$ & $-8.8 /-5.6$ & No & $\begin{array}{l}5 / 6 \\
\text { (Continued) }\end{array}$ \\
\hline
\end{tabular}


Table. Continued

\begin{tabular}{|c|c|c|c|c|c|c|}
\hline Trial Acronym & $\begin{array}{l}\text { Patient } \\
\text { Number }\end{array}$ & Follow-Up, y & $\begin{array}{l}\text { Hypertensive } \\
\text { Patients, \% }\end{array}$ & $\begin{array}{c}\text { SBP/DBP } \\
\text { Difference, } \mathrm{mm} \mathrm{Hg}\end{array}$ & $\begin{array}{c}\text { Baseline } \\
\text { BP-Lowering Drugs }\end{array}$ & $\begin{array}{c}\text { Quality Assessment } \\
\text { vScore }\end{array}$ \\
\hline TEST ${ }^{56}$ & 720 & 2.3 & $100 \%$ & $-4 /-4$ & No & $5 / 6$ \\
\hline TOMHS ${ }^{57}$ & 902 & 4.4 & $100 \%$ & $-6.8 /-3.6$ & No & $4 / 6$ \\
\hline USPHS $^{58}$ & 389 & 7.0 & $100 \%$ & $-15.9 /-10$ & No & $4 / 6$ \\
\hline$V A 1^{9}$ & 143 & 1.5 & $100 \%$ & $-39.4 /-26.9$ & No & $5 / 6$ \\
\hline$V A 2^{59}$ & 380 & 3.8 & $100 \%$ & $-34.4 /-18.3$ & No & $5 / 6$ \\
\hline VA-NHLB| ${ }^{60}$ & 1012 & 1.5 & $100 \%$ & $\mathrm{NR} /-5.9$ & No & $4 / 6$ \\
\hline Wolff ${ }^{8}$ & 87 & 1.4 & $100 \%$ & $-32.9 /-19.8$ & No & $5 / 6$ \\
\hline \multicolumn{7}{|c|}{ Intentional, more vs less intense BP-lowering trials } \\
\hline AASK $^{61}$ & 1094 & 4.0 & $100 \%$ & $-13 /-7$ & Yes & $3 / 6$ \\
\hline $\mathrm{ABCD}-\mathrm{HT}^{62}$ & 470 & 5.0 & $100 \%$ & $-6 /-8$ & No & $3 / 6$ \\
\hline $\mathrm{ACCORD}^{63}$ & 4733 & 4.7 & $87 \%$ & $-14.2 /-6.4$ & Yes & $6 / 6$ \\
\hline $\mathrm{BBB}^{64}$ & 2127 & 4.9 & $100 \%$ & $-11 /-8$ & Yes & $5 / 6$ \\
\hline Cardio-SIS 65 & 1111 & 2.0 & $100 \%$ & $-3.8 /-1.5$ & Yes & $3 / 6$ \\
\hline Fogari66 & 309 & 4.0 & $100 \%$ & $-8.9 /-4.6$ & No & $4 / 6$ \\
\hline $\mathrm{HOT}^{67}$ & 18990 & 3.8 & $100 \%$ & $-2.8 /-3.1$ & No & $5 / 6$ \\
\hline JATOS $^{68}$ & 4418 & 2.0 & $100 \%$ & $-9.6 /-3.3$ & Yes & $5 / 6$ \\
\hline MDRD ${ }^{69}$ & 840 & 2.2 & $86 \%$ & $-10.7 /-6.9$ & Yes & $3 / 6$ \\
\hline REIN-2 $2^{70}$ & 335 & 1.6 & $60 \%$ & $-4 /-2$ & Yes & $2 / 6$ \\
\hline SANDS $^{71}$ & 499 & 3.0 & $100 \%$ & $-7 /-6$ & Yes & $4 / 6$ \\
\hline SPS- $3^{72}$ & 3020 & 3.7 & $75 \%$ & $-12.1 / \mathrm{NR}$ & Yes & $5 / 6$ \\
\hline UKPDS $^{73}$ & 1148 & 8.4 & $100 \%$ & $-10 /-5$ & Yes, low & $5 / 6$ \\
\hline VALISH $^{74}$ & 3260 & 2.9 & $100 \%$ & $-5.4 /-1.7$ & Yes & $5 / 6$ \\
\hline \multicolumn{7}{|c|}{ Nonintentional blood pressure lowering trials } \\
\hline ACTIVE-I & 9016 & 4.1 & $88 \%$ & $-2.9 /-1.9$ & Yes & $6 / 6$ \\
\hline $\mathrm{AlPRI}^{76}$ & 583 & 3.0 & $82 \%$ & $-10.1 /-6.2$ & Yes & $4 / 6$ \\
\hline BENEDICT-A ${ }^{77}$ & 1204 & 3.6 & $57 \%$ & $-2.3 /-2$ & Yes & $3 / 6$ \\
\hline DEMAND ${ }^{78}$ & 380 & 3.8 & $44.2 \%$ & $-1.4 /-2.0$ & Yes & $3 / 6$ \\
\hline DIABHYCAR $^{79}$ & 4912 & 3.9 & $56 \%$ & $-2 /-0.7$ & Yes & $5 / 6$ \\
\hline DIRECT-2 ${ }^{80}$ & 1905 & 4.7 & $62 \%$ & $-3.9 /-2$ & Yes & $5 / 6$ \\
\hline DREAM ${ }^{81}$ & 5269 & 3.0 & $43.5 \%$ & $-4.2 /-2.4$ & Yes & $5 / 6$ \\
\hline GISSI-AF 82 & 1442 & 1.0 & $85.4 \%$ & $-3 / \mathrm{NR}$ & Yes & $3 / 6$ \\
\hline HOPE ${ }^{83}$ & 9297 & 5.0 & $46.9 \%$ & $-4.4 /-1.7$ & Yes & $5 / 6$ \\
\hline MICROHOPE ${ }^{84}$ & 3577 & 4.5 & $56 \%$ & $-3.3 /-1.6$ & Yes & \\
\hline IDNT ${ }^{85}$ & 1715 & 2.6 & $100 \%$ & $-3.5 /-3$ & Yes & $5 / 6$ \\
\hline IRMA-2 $2^{86}$ & 590 & 2.0 & $100 \%$ & $-2 / 0$ & No & $4 / 6$ \\
\hline I-PRESERVE ${ }^{87}$ & 4128 & 4.1 & $88 \%$ & $-2.6 /-2$ & Yes & $6 / 6$ \\
\hline Lewis $^{88}$ & 409 & 3.0 & $75.5 \%$ & $-2 /-2.5$ & Yes & $3 / 6$ \\
\hline NAVIGATOR ${ }^{89}$ & 9306 & 6.5 & $77.5 \%$ & $-3 /-2$ & Yes & $6 / 6$ \\
\hline NICOLE ${ }^{90}$ & 819 & 3.0 & $40 \%$ & $-8 /-3$ & No & $3 / 6$ \\
\hline ORIENT ${ }^{91}$ & 577 & 3.2 & $93 \%$ & $-4.5 /-1$ & Yes & $5 / 6$ \\
\hline PEACE ${ }^{92}$ & 8290 & 4.8 & $45.5 \%$ & $-2 /-1.2$ & Yes & $5 / 6$ \\
\hline PROFESS ${ }^{93}$ & 20332 & 2.5 & $74 \%$ & $-4.6 /-2.2$ & Yes & $6 / 6$ \\
\hline RENAAL ${ }^{94}$ & 1513 & 3.4 & $93 \%$ & $-2.7 /-1$ & Yes & $5 / 6$ \\
\hline ROADMAP ${ }^{95}$ & 4447 & 3.2 & $82 \%$ & $-3 /-1.9$ & Yes & $6 / 6$ \\
\hline TRANSCEND $^{96}$ & 5926 & 4.7 & $76.4 \%$ & $-4.6 /-2.2$ & Yes & $6 / 6$ \\
\hline
\end{tabular}

In all RCTs in which randomization was to $>2$ groups, comparisons are between the average of all treatment groups and placebo ${ }^{32,44,45,57,77,78,85}$ or between combination therapy and average of monotherapies. ${ }^{66}$ In HOT ${ }^{50}$ comparison is between groups randomized to DBP target $<80$ vs DBP targets $<85$ and $<90 \mathrm{~mm} \mathrm{Hg}$ together. BP indicates blood pressure; DBP, diastolic blood pressure; NR, not reported; and SBP, systolic blood pressure. 


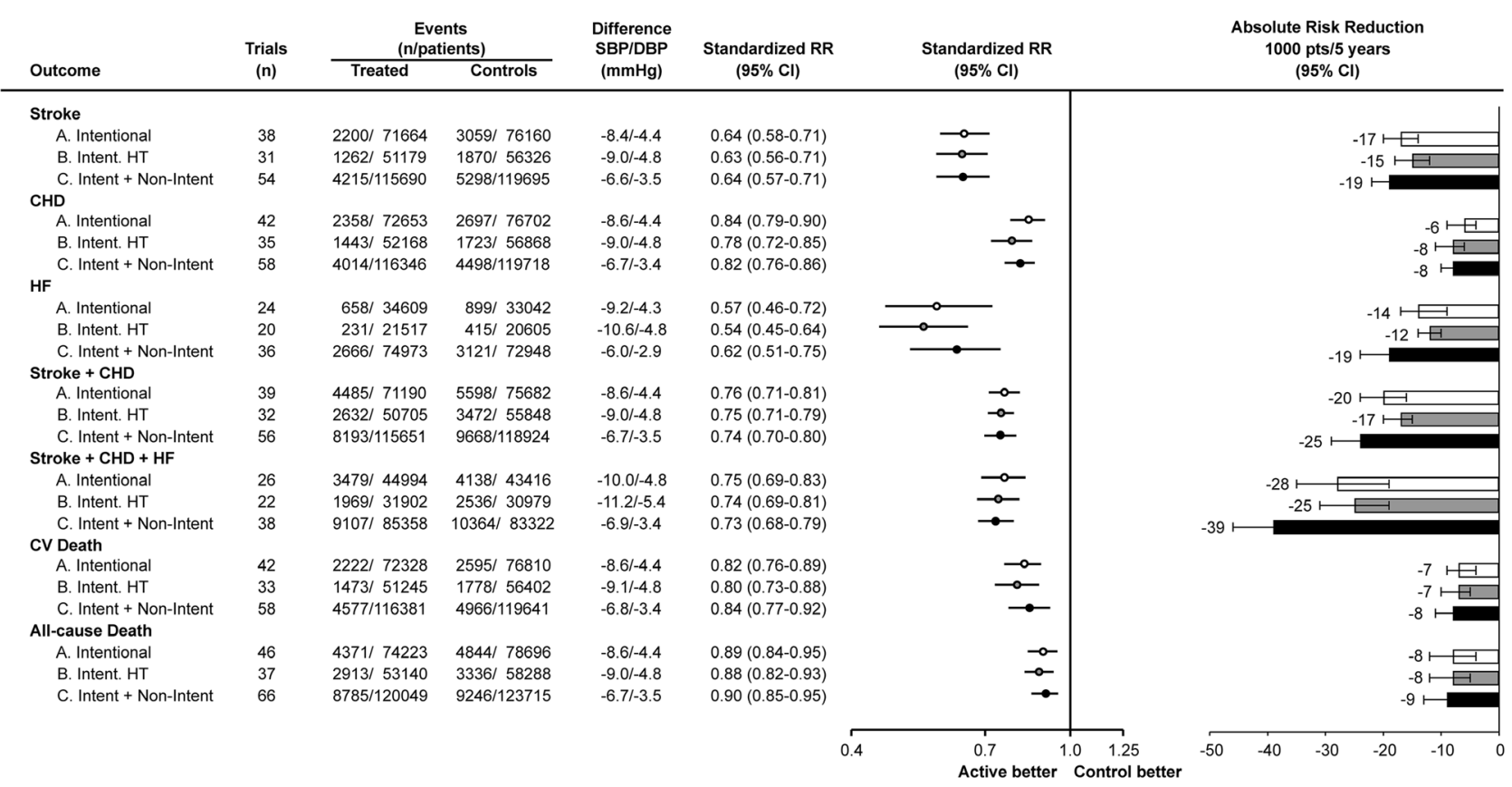

Figure 1. Relative and absolute risk reduction of various outcomes in trials of blood pressure (BP) lowering. A, Intentional BPlowering trials. B, Intentional BP-lowering trials exclusively in hypertensive (HT) patients. C, Intentional and nonintentional BP-lowering trials together. All major types of cardiovascular (CV) events and death are significantly reduced by BP-lowering treatment, the effects being particularly large for stroke and heart failure (HF). Absolute risk reductions are also substantial. There are no major differences in the effects when only intentional BP-lowering trials are considered (A, primary analysis), only intentional trials exclusively enrolling hypertensive patients are analyzed (B, sensitivity analysis), and both intentional and nonintentional trials are considered together (C, secondary analysis). Standardized Mantel-Haenszel risk ratio (RR) is to a systolic BP (SBP)/diastolic BP (DBP) difference of 10/5 mm Hg. The column absolute risk reduction reports the number and $95 \%$ confidence interval $(\mathrm{Cl})$ of events prevented for every 1000 patients treated for 5 years with a standardized RR. CHD indicates coronary heart disease (Data derived from Thomopoulos et al23).

control groups of 10/5 $\mathrm{mm} \mathrm{Hg}$ ) and risks of coronary heart disease (CHD) events and cardiovascular and all-cause mortality being also significantly reduced but to a lesser extent $(16 \%$, $18 \%$, and $11 \%$, respectively; Figure 1, row: intentional). After excluding those intentional RCTs in which not all enrolled patients were hypertensives, ${ }^{28,29,32,47,48,63,69,70,72}$ only slightly increased relative risk reductions were found (Figure 1, intent. hypertensive). Inclusion of nonintentional BP-lowering trials (Figure 1, intent+nonintent) did not substantially change the relative risk reductions either. Figure 1 also shows that absolute reduction of the risk of all outcomes was significantly and substantially reduced by a standardized SBP/DBP reduction of 10/5 mm Hg: for example, in intentional BP-lowering RCTs, 28 major cardiovascular events (composite of stroke, CHD, and HF) could be prevented for every 1000 patients treated for 5 years, with a number of patients needed to treat of only $36 .^{23}$

The relationship of different outcome reductions to the extent of BP reductions was investigated by metaregression analyses of the 47 RCTs of intentional BP lowering. ${ }^{23}$ The natural logarithm of the RR of stroke was significantly related to the extent of SBP, DBP, and PP reductions and that of cardiovascular mortality to SBP and PP reductions. However, RRs of CHD and all-cause mortality did not show significant relationships with any BP reduction..$^{23}$ When metaregressions were calculated by using percent changes in $\mathrm{BP}$, which were similar for SBP, DBP, and PP (maximum reductions of $22 \%$, $22 \%$, and $25 \%$, respectively), regression coefficients were similar for all types of BP (Figure 2), ${ }^{23}$ indicating no preferential relationship of outcome reduction with any BP parameter. The finding that the relationships of the BP reductions were with the logarithm of the outcome RRs adds the information that progressively greater BP reductions result in progressively lower increments of risk reductions. This parallels the semilogarithmic relationship between BP and cardiovascular event rates in observational studies. ${ }^{97}$

\section{Effects of BP Lowering Produced by Drugs Belonging to Different Classes of Antihypertensive Agents}

In the 68 RCTs used to estimate quantitatively the efficacy of BP lowering in preventing different types of cardiovascular outcomes, the BP lowering was obtained by administering drugs belonging to different pharmacological classes. There is an obvious interest in further investigating whether BP lowering by any of the major classes of antihypertensive therapy can be shown to be effective in reducing all or part of cardiovascular outcomes. Several meta-analyses have approached this problem in the past, ${ }^{16-20,98-106}$ but none of them has been comprehensive of all BP-lowering RCTs from 1966 to the end of 2013 and simultaneously exclusive of RCTs comparing different active regimens (the latter type of trials aim at avoiding, instead of inducing, a between-group BP difference) and of RCTs investigating antihypertensive drugs in the treatment of conditions different from hypertension (such as myocardial infarction and $\mathrm{HF}$ ). 

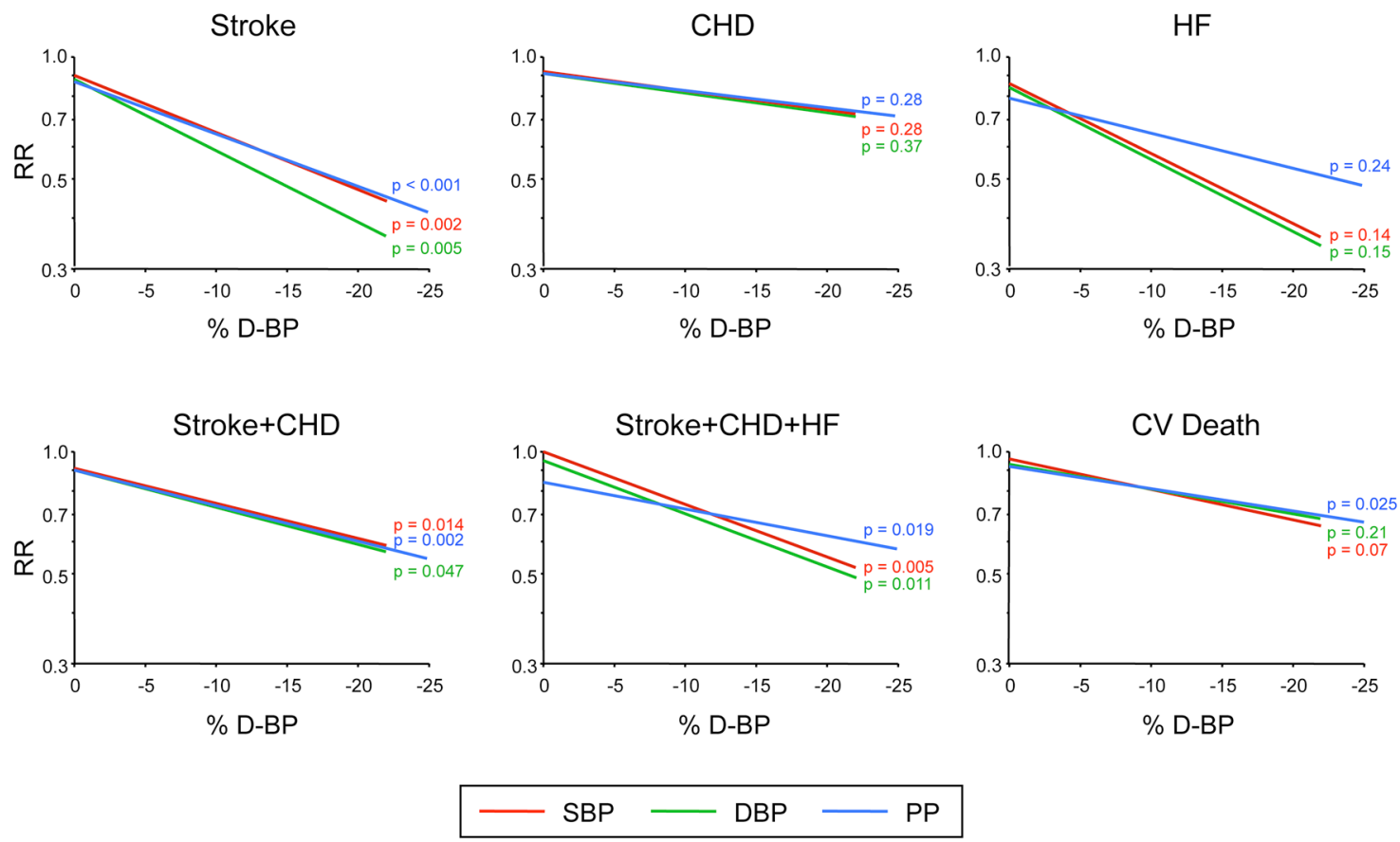

Figure 2. Relationships of outcome reductions to percent blood pressure (BP) reductions. Metaregressions of Mantel-Haenszel risk ratios (RR) on percent BP differences (BP differences of active group minus placebo or less active group as percentage of ontreatment BP in the placebo or less active group). Regressions relative to systolic BP (SBP) are in red, those relative to diastolic BP (DBP) in green, those relative to pulse pressure (PP) are in blue. Reductions in stroke, composite of stroke and coronary heart disease (CHD), composite of stroke, CHD, and heart failure (HF), and cardiovascular (CV) death are proportional to the reductions of SBP, DBP, and PP, with no closer relationship to any type of BP. Note that the logarithmic nature of the relationship implies that risk reduction increases to a progressively smaller extent the larger the BP reduction. D-BP indicates blood pressure difference (Reprinted from Thomopoulos et al ${ }^{23}$ with permission of the publisher. Copyright (C2014, Wolters Kluwer Health).

Of the 68 BP-lowering RCTs we have identified, 55 were suitable for drug-class meta-analyses. ${ }^{26}$ Twelve $\operatorname{RCTs}^{30,34,37,38,42-47,50,51,60}$ (48 898 patients) compared a diuretic with no treatment. SBP/DBP differences of $\approx-12 /-5 \mathrm{~mm} \mathrm{Hg}$ were accompanied by significant reductions of all outcomes, including mortality (Figure 3A). The same results were obtained by limiting analyses to 8 RCTs using low-dose diuretics, ${ }^{34,42,43,45-47,50,51}$ as currently prescribed. Eight small RCTs (1786 patients) $)^{8,9,31,33,40,52,58,59}$ that used a choice of centrally acting drugs (reserpine and methyldopa) often in combination with thiazide or hydralazine were analyzed together and provided evidence of significant reductions of stroke, HF, major cardiovascular events, and cardiovascular mortality ${ }^{26}$ (Figure 3B). Five RCTs ${ }^{39,44,45,56,73}$ (18724 individuals) provided evidence that BP lowering by $\beta$-blockers (SBP/DBP difference, $-10 /-5 \mathrm{~mm} \mathrm{Hg}$ ) can significantly reduce stroke, $\mathrm{HF}$, and major cardiovascular events (Figure 3C). Evidence of significant reduction in cardiovascular mortality was achieved only when the Swedish Trial in Old Patients with Hypertension (STOP) trial ${ }^{53}$ using a choice between $\beta$-blockers and diuretics as active drugs was included. ${ }^{26}$

The design of BP-lowering RCTs comparing calcium antagonists, angiotensin-converting enzyme inhibitors, and angiotensin receptor blockers with placebo (with tested drugs and placebo often being added on a background of pre-existing antihypertensive therapy) was such that smaller SBP/ DBP differences were achieved. Nonetheless, evidence of significant reductions of stroke, major cardiovascular events, and cardiovascular and all-cause deaths by 10 RCTs
(30359 patients) comparing calcium antagonists with placebo $^{28,32,35,41,54,55,66,70,85,90}$ (Figure 3D), evidence of significant reductions of stroke, $\mathrm{CHD}, \mathrm{HF}$, and major cardiovascular events by 12 RCTs (35 707 patients) using angiotensin-converting enzyme inhibitors $32,42,48,66,73,76,77,79,81,83,88,92$ (Figure 3E), and evidence of significant reductions in stroke, HF, and major cardiovascular events by 13 RCTs (65256 patients) using angiotensin receptor blockers ${ }^{49,75,80,82,85-87,89,91,93-96}$ (Figure 3F) were obtained..$^{26}$ Among calcium antagonist RCTs, it was possible to separately analyze, in a sensitivity meta-analysis, 4 RCTs $^{35,41,54,55}$ enrolling exclusively hypertensive patients without or with minimal background treatment (in this way, more similar to RCTs testing diuretics or $\beta$-blockers versus placebo), and this meta-analysis also showed significant reductions of CHD and HF. Similar sensitivity analyses could not be done for angiotensin-converting enzyme inhibitors and angiotensin receptor blockers because of the absence of large RCTs done in exclusively hypertensive patients without background therapy. ${ }^{26}$

In conclusion, BP lowering by all classes of antihypertensive drugs is accompanied by significant reductions of stroke and major cardiovascular events. This supports the concept that reduction of these events is because of BP lowering per se rather than specific drug properties, a concept shared by the European Society of Hypertension-European Society of Cardiology hypertension guidelines, ${ }^{13}$ which, on this basis, recommend all major classes of antihypertensive agents to initiate treatment. However, evidence of risk reduction of other cardiovascular events and, particularly, mortality has 


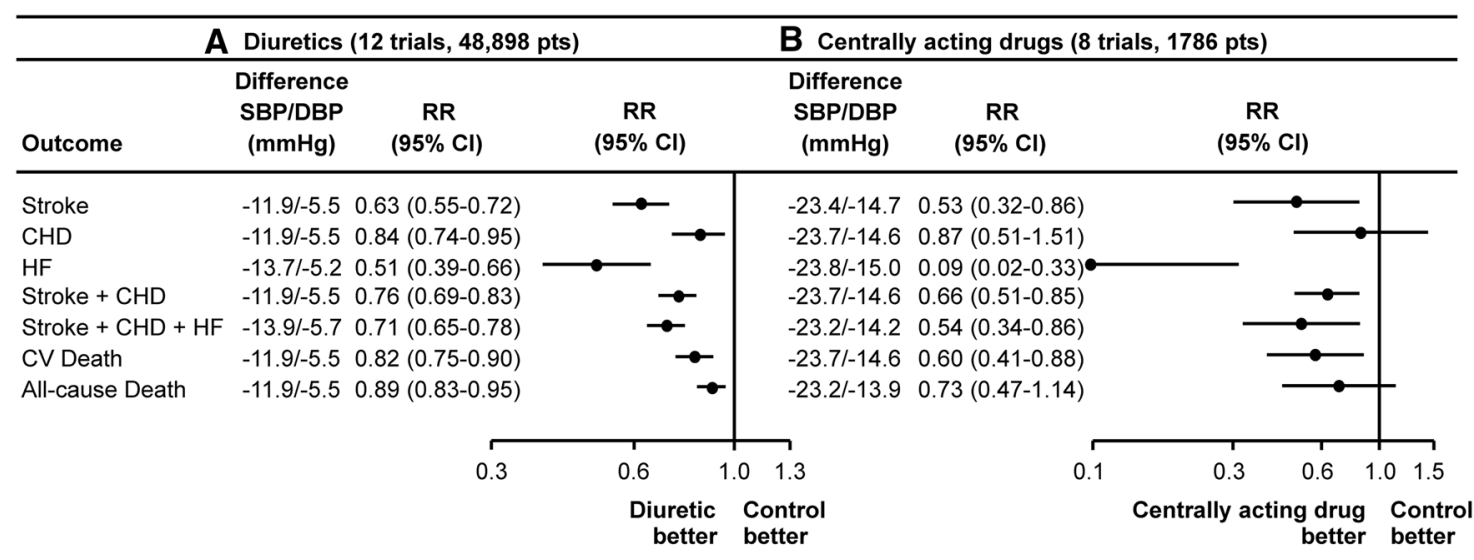

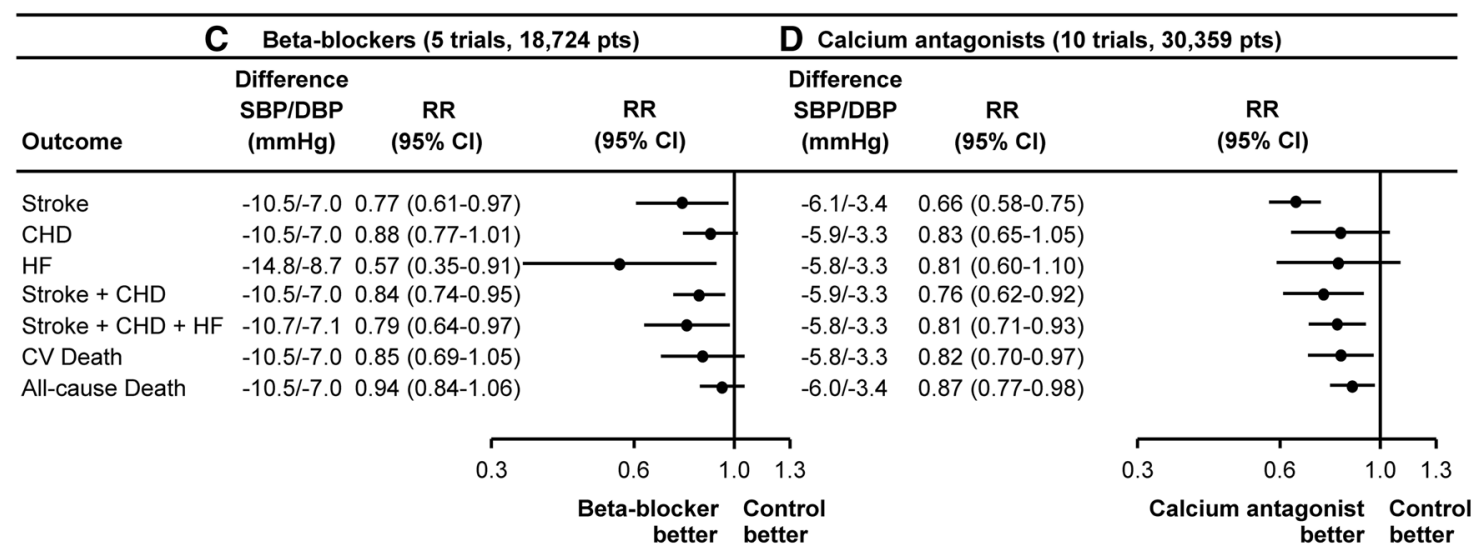

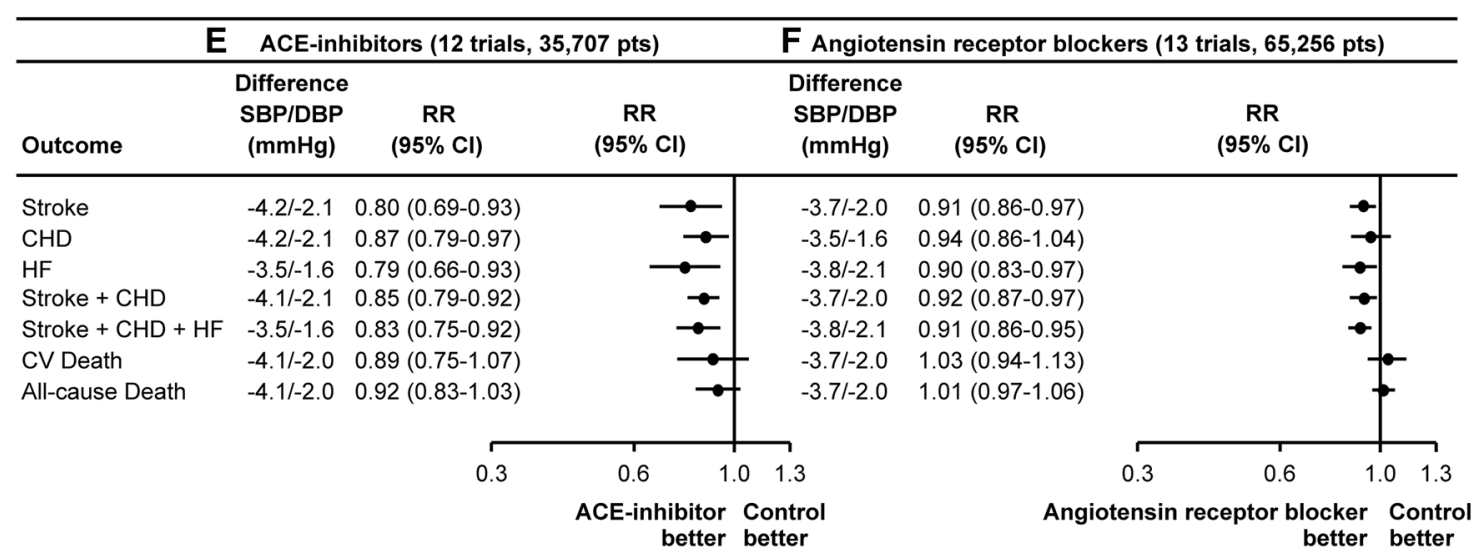

Figure 3. Relative risk reduction of various outcomes in trials of blood pressure (BP) lowering by different classes of drugs. A, Diuretics. B, Centrally acting drugs. C, $\beta$-blockers. D, Calcium antagonists. E, Angiotensin-converting enzyme (ACE) inhibitors. $\mathbf{F}$, Angiotensin receptor blockers. BP lowering by all classes of antihypertensive drugs is accompanied by significant reductions of stroke and composite cardiovascular (CV) events, but evidence of risk reduction of coronary heart disease (CHD) and heart failure (HF) and particularly mortality has been found to date with some drug classes only. Note, however, that BP differences between active and placebo treatments have been much smaller with more recent classes of drugs (D-F versus A-C). Cl indicates confidence intervals; DBP, diastolic blood pressure; pts, patients; RR, Mantel-Haenszel risk ratios; and SBP, systolic blood pressure (Data derived from Thomopoulos et al ${ }^{26}$ ).

been obtained to date with some drug classes only. There were marked differences in trial design (in older trials, treatment was initiated by either the active drugs being tested or placebo, whereas in more recent trials, the active drugs being tested or placebo were added as the last drug on a background of pre-existing antihypertensive therapy), total cardiovascular risk (from a minimum of $3.7 \%$ cardiovascular deaths in 5 years in $\beta$-blocker RCTs to a maximum of $7.9 \%$ in angiotensin receptor blocker RCTs), SBP/DBP differences between active and placebo groups (from $-3.7 /-2.0 \mathrm{~mm} \mathrm{Hg}$ in angiotensin receptor blocker RCTs to $-23.5 /-14.5 \mathrm{~mm} \mathrm{Hg}$ in RCTs using centrally active drugs), and sample size (from as few 
as 1786 patients in whom centrally active compounds were studied up to as many as 65256 patients in whom angiotensin receptor blockers were studied). ${ }^{26}$ Therefore, comparisons of meta-analyses of different class-specific placebo-controlled RCTs seem unwarranted. The relative effectiveness of different drug classes can only be estimated by their head-to-head comparison in the same trial. In concluding our recent metaanalyses of class-specific placebo-controlled RCTs, we have remarked that these meta-analyses must be considered a necessary background for the interpretation of the results of trials comparing head-to-head different active therapeutic regimens and their meta-analyses. Often similar incidences of a given outcome in active regimens comparative trials are interpreted as similar benefits of the 2 active regimens, but the data we have reported are a warning that similar outcome incidences can be defined as benefits only when $\geq 1$ of the agents tested has been shown to significantly reduce risk of that outcome in placebo-controlled trials. ${ }^{26}$

\section{Effects of BP-Lowering Treatment on Various Outcomes in Individuals at Different Levels of High BP}

Untreated hypertensive patients are usually stratified in hypertension grades (stages in the US style) according to SBP/DBP levels to guide therapeutic decisions. ${ }^{13,107,108}$ However, trials of antihypertensive therapy were rarely designed by stratifying patients in this way, and it is no surprise that guidelines markedly differ in their recommendations especially about initiation of antihypertensive drug treatment in grade 1 hypertension. ${ }^{13,14,108,109}$ Some placebo-controlled trials, mostly in the 1970 s and 1980s, were focused on so-called mild hypertension, ${ }^{30,37,44,57,58}$ but its definition was different from the current one of grade 1 (or stage 1) hypertension. ${ }^{11,12}$

In lack of specific trials, meta-analyses can follow 2 different approaches to estimate and compare the effects of BPlowering treatment in patients at different levels of initial BP: (1) to identify individuals with different hypertension grades in each trial and meta-analyze their data separately according to baseline hypertension grade and (2) to classify and metaanalyze trials according to average baseline SBP and DBP as grade 1,2 , or 3 trials. The major limitation of the first approach, in addition to being an analysis of subgroups defined post hoc, is the need to have individual patient data available, which markedly limits the number of trials that can be analyzed by any group of investigators with the loss of statistical power and possible selection bias. A Cochrane collaboration meta-analysis ${ }^{110}$ limited to individuals in mild hypertension trials matching the BP values now defining grade 1 hypertension had indeed limited statistical power to detect significant risk reductions, although stroke reduction came close to statistical significance. A meta-analysis by Czernichow et al ${ }^{111}$ of a larger number of trials including individuals at different baseline BP levels showed significant risk reductions at all BP levels, but a large proportion of the individuals were receiving background antihypertensive treatment at the trial beginning and were therefore different from the individuals for whom decisions on initiation of drug treatment are taken. Inclusion of patients under antihypertensive treatment at baseline and patients with cardiovascular conditions different from hypertension (mostly acute myocardial infarction and $\mathrm{HF}$ ) makes the meta-analyses by Law et $\mathrm{al}^{20}$ and Thompson et $\mathrm{al}^{112}$ scarcely contributing to the issue of BP levels at which drug treatment should be initiated. A most recent meta-analysis of the BPLTTC has used individual data of patients with SBP/ DBP in the grade 1 range from 10 BP-lowering RCTs and reported that $\mathrm{BP}$ lowering induced a significant reduction of the risk of stroke and cardiovascular and total mortality, but most of the patients had diabetes and mortality reduction lost statistical significance after patients under baseline antihypertensive treatment were excluded. ${ }^{113}$

The second approach has the advantage of allowing the inclusion of all BP-lowering trials provided that no antihypertensive treatment was present at randomization; so that the average SBP/DBP baseline values can be used for classifying each trial in a given hypertension grade. In this way, a large number of trials can be analyzed; statistical power is high, and selection bias is avoided. The limitation is that by using the mean BP values for defining hypertension grade, the analyses are going to include a number, although a minority, of patients whose BP are out of the ranges defining a particular hypertension grade.

Of the 68 BP-lowering RCTs we have considered, 32 could be analyzed to evaluate the effect of baseline BP levels because no antihypertensive treatment was present at baseline (minimum treatment in 3). ${ }^{24}$ Six RCTs (16036 individuals)

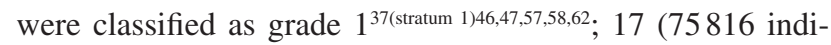
viduals) as grade $2,8,30,35,40,41,43,44,49-51,54-56,59,66,67,73$; and 9 (12507 individuals) as grade 3 hypertension. 9,33,34,37(stratum 2-3),39,42,45,52,53 Between-treatment SBP/DBP differences tended to be larger in grade 3 RCTs, all RRs in Figure 4 were standardized to a SBP/DBP difference of 10/5 $\mathrm{mm} \mathrm{Hg}$. Even in grade 1 hypertension, BP lowering was associated with significant relative risk reductions of stroke, $\mathrm{CHD}$, the composite of stroke and $\mathrm{CHD}$, and cardiovascular and all-cause mortality. Only a marked reduction in the risk of HF did not reach statistical significance owing to the extremely wide confidence intervals because of the fact that data on HF were available in 2 grade 1 RCTs only. Figure 4 also shows that relative risk of all outcomes was significantly reduced by BP lowering in grade 2 hypertensives, and the same was true in grade 3 , with the only exception of all-cause death. Trend analysis demonstrated that relative risk reduction of all outcomes did not significantly change at different levels of baseline BP $(P$ always $>0.05) .{ }^{24}$

This is the first demonstration that all grades of hypertension (correctly defined in the absence of concomitant treatment) are similarly susceptible to the beneficial effect of BP lowering. Evidence of BP-lowering benefits in grade 1 hypertensives is particularly important because nowadays, these hypertensives are by far the most prevalent among those seeking counseling about drug treatment initiation. Because of the current debate about indications for BP-lowering drug treatment in grade 1 hypertensives, when their total cardiovascular risk is in the low-moderate range, a secondary analysis was done including trials or trial subgroups with mean baseline SBP/DBP values in the grade 1 range and a low-moderate total cardiovascular risk, as indicated by a cardiovascular death incidence $<5 \%$ in 10 years in the control groups ${ }^{36,38,46,57,58}$ : risk of stroke, CHD, 


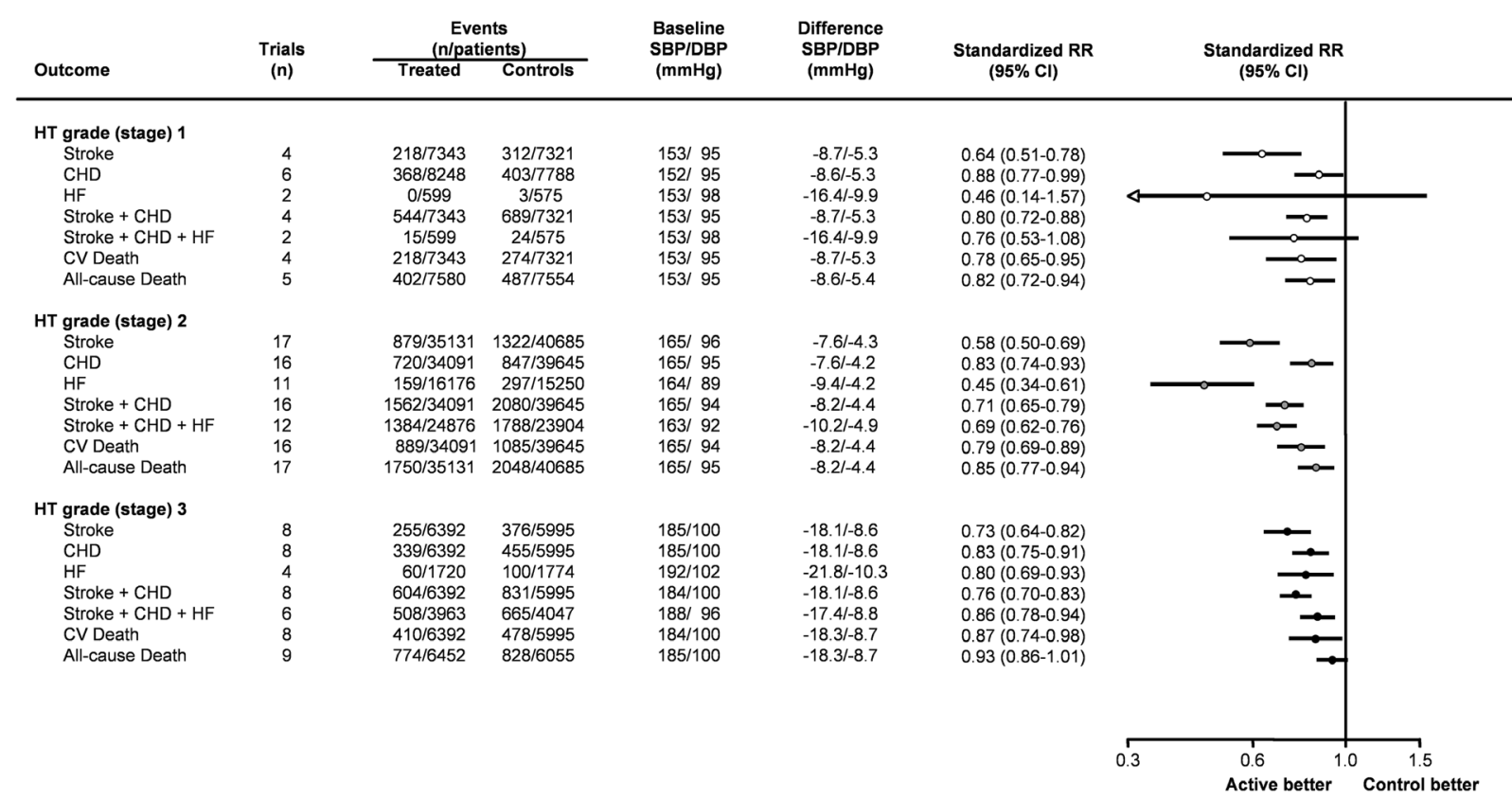

Figure 4. Effects of blood pressure (BP) lowering in trials stratified by mean hypertension (HT) grade (stage) at randomization. Cardiovascular (CV) outcomes are significantly reduced at all grades of HT with no significant difference in relative risk reduction between different grades $(P$ for trend always $>0.05)$. Standardized Mantel-Haenszel risk ratio (RR) is to a systolic BP (SBP)/diastolic (DBP) difference of $10 / 5 \mathrm{~mm} \mathrm{Hg}$. CHD indicates coronary heart disease; Cl, confidence intervals; HF, heart failure; and n, number (Data derived from Thomopoulos et $\mathrm{al}^{24}$ ).

major cardiovascular events, and all-cause death were significantly reduced by BP-lowering treatment (Figure 5), ${ }^{23}$ thus providing further support to those guidelines ${ }^{13,14}$ favoring, at least as a prudent approach, the prescription of BP-lowering drugs to all adult individuals whose BP values remain $\geq 140 / 90$ $\mathrm{mm} \mathrm{Hg}$ despite adequate lifestyle interventions.

\section{Effects of BP-Lowering by Treatment to SBP and DBP Levels Below Versus Above Predetermined Cut Offs}

Prominent among practical questions of antihypertensive drug management is that about the level to which BP should be brought by treatment to maximize outcome reduction. In spite of the importance of the question, only few BP-lowering RCTs have investigated the problem. Most of these trials have tested the effects of more or less intense lowering, however, without a precise BP target; others have used only DBP targets; others have used noncardiovascular outcomes (such as renal function or left ventricular hypertrophy) as primary end point; none of them had sufficient statistical power to answer the question. Because of the practical importance of the question, a large number of authors have exercised themselves in post hoc analyses of RCT data by correlating the incidences of cardiovascular outcomes with individual levels of treatment achieved SBP or DBP. These analyses have usefully contributed to raising 2 opposite hypotheses, namely (1) the lower is the achieved BP the better is the treatment outcome and (2) the J-curve hypothesis suggesting that at low BP values, cardiovascular risk may be less effectively prevented than at intermediate BP levels. ${ }^{114}$ It is obvious, however, that the

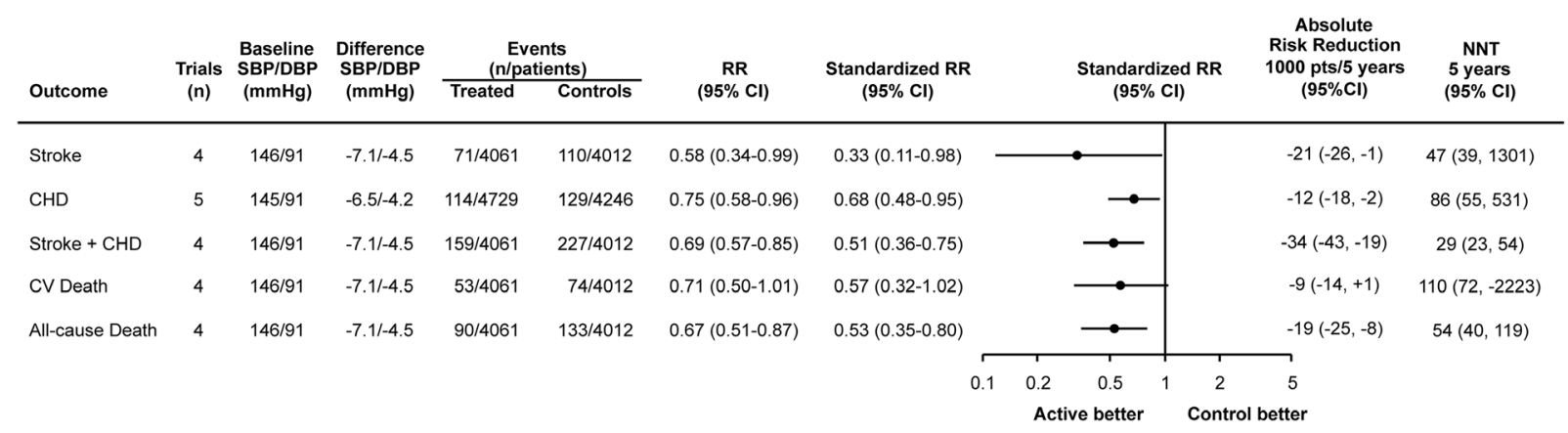

Figure 5. Effects of blood pressure (BP) lowering in trials with average baseline BP in grade 1 and average low-moderate cardiovascular (CV) risk. Note significant reductions of relative and absolute risk of stroke, coronary heart disease (CHD), composite of stroke and CHD, and all-cause death. Standardized Mantel-Haenszel risk ratio (RR) is to a systolic BP (SBP)/diastolic BP (DBP) difference of $10 / 5 \mathrm{~mm} \mathrm{Hg}$. The column absolute risk reduction reports number ( $\mathrm{n}$; and $95 \%$ confidence interval [Cl]) of events prevented for every 1000 patients (pts) treated for 5 years with a standardized RR. Numbers needed to treat (NNT) are numbers (and 95\% Cl) of patients needed to treat for 5 years to prevent 1 event. CV death rate in the control group (index of CV risk) was $4.5 \%$ in 10 years (Reprinted from Thomopoulos et $\mathrm{a}^{24}$ with permission of the publisher. Copyright (C2014, Wolters Kluwer Health). 
approach of analyzing RCTs by classifying individual data on the basis of BP values achieved during treatment independent of treatment assignment leads to the loss of randomization, and any meta-analysis of these studies becomes one of the observational rather than randomized studies. ${ }^{114}$

To preserve randomization, a meta-analysis investigating the effects of different SBP (or DBP) levels achieved by treatment on cardiovascular outcomes should (1) analyze RCTs in their entirety without recourse to individual data; (2) classify them according to average SBP (or DBP) levels separately achieved in the active (or more active) and placebo (or less active) treatment arms; and (3) group the different RCTs according to clinically meaningful SBP (or DBP) cut offs when average achieved BP values of the placebo (or less active) arm are above and those of the active (or more active) arm are below that particular cut off.

In 32 of the 68 BP-lowering RCTs we have identified, ${ }^{23}$ treatment lowered BP across 3 predeterminate SBP cut offs (140-149 versus $\geq 150$; $130-139$ versus $\geq 140$; $<130$ versus $\geq 130 \mathrm{~mm} \mathrm{Hg}$ ) and in 29 across 2 predeterminate DBP cut offs ( $<90$ versus $\geq 90$; $<80$ versus $\geq 80 \mathrm{~mm} \mathrm{Hg}$ ). As illustrated in Figure 6, the meta-analysis of 8 trials (13841 individuals $)^{9,34,40,43,50,51,64,73}$ allowing comparison of SBP values across the cut off of $150 \mathrm{~mm} \mathrm{Hg}$ showed that all outcomes (stroke, CHD, HF, and cardiovascular and all-cause mortality) were significantly reduced by lowering SBP below 150 $\mathrm{mm} \mathrm{Hg}{ }^{24}$; the meta-analysis of 16 RCTs (82421 individuals $)^{29,35,37,44,46,48,58,59,65-68,74,76,77,84}$ allowing comparison of SBP values across the cut off of $140 \mathrm{~mm} \mathrm{Hg}$ also showed that all outcomes, with the only exception of HF, were significantly reduced by lowering SBP below $140 \mathrm{~mm} \mathrm{Hg},{ }^{24}$ whereas the meta-analysis of 8 RCTs (31970 individuals) $)^{38,57,61,63,69,72,81,92}$ allowing comparison of SBP values across the cut off of 130 $\mathrm{mmHg}$ showed that only stroke and all-cause death were significantly reduced by lowering SBP below $130 \mathrm{~mm} \mathrm{Hg} .{ }^{24}$ Furthermore, trend analysis showed that absolute risk reductions of stroke, HF, major cardiovascular events, and cardiovascular death became progressively smaller, the lower were the achieved SBP values being compared. ${ }^{24}$

Meta-analysis of 13 RCTs (41790 individuals) $)^{30,31,34,37,40-42,44,46,53,58,59,64}$ allowing comparison of DBP values across the cut off of $90 \mathrm{~mm} \mathrm{Hg}$ and a separate meta-analysis of 16 RCTs (65 875 individuals) $)^{39,43,45,48,49,55,57,61,62,65,69,81,85,88,89,93}$ allowing comparison of DBP values across the cut off of 80 $\mathrm{mm} \mathrm{Hg}$ showed similar reduction of cardiovascular outcomes independently of the chosen cut off. However, when RCTs with a baseline DBP of $<90 \mathrm{~mm} \mathrm{Hg}$ (predominantly isolated systolic hypertension) were excluded from RCTs with achieved DBP across the cut off of $80 \mathrm{~mm} \mathrm{Hg}$, lowering DBP to $<80 \mathrm{~mm} \mathrm{Hg}$ was associated only with significant reductions in stroke and composite cardiovascular events including stroke.

Although meta-analyses are not substitutes for trials directly investigating a clinical question (in this case, the optimal SBP and DBP targets), the results of the meta-analyses summarized above provide support to present opinion-based recommendations ${ }^{13,14,108}$ aiming treatment at SBP/DBP targets of $<140 / 90 \mathrm{~mm} \mathrm{Hg}$, with SBP values just $<130$ and DBP values just $<80 \mathrm{~mm} \mathrm{Hg}$ being safe and potentially beneficial particularly about stroke.

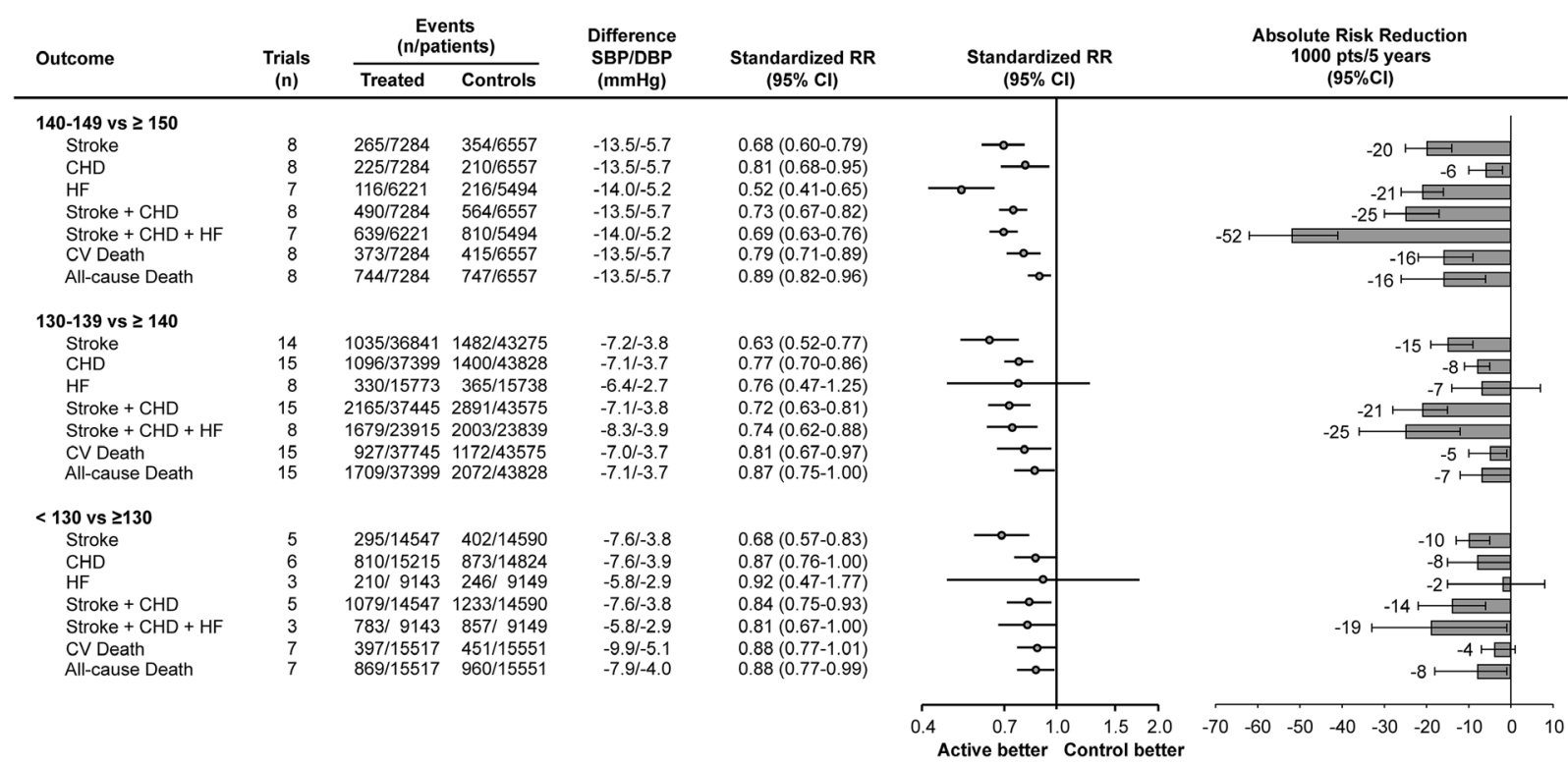

Figure 6. Effects of blood pressure (BP) lowering in trials with mean on-treatment systolic BP (SBP) below and above different cut offs. Mean SBP/diastolic BP (DBP) achieved on treatment were for SBP cut off 150, 143.3/76.4 (active) and 157.1/82.2 (control), cut off 140,137.2/81.1 and 144.3/84.8; cut off 130, 126.8/78.7 and 136.8/83.7 mm Hg. Lowering SBP just below when compared with just above the cut offs of 150 or $140 \mathrm{~mm} \mathrm{Hg}$ is able to reduce almost all types of outcomes, whereas lowering SBP just below when compared with just above the $130 \mathrm{~mm} \mathrm{Hg}$ cut off only stroke and all-cause death is significantly reduced. Standardized Mantel-Haenszel risk ratio (RR) is to a SBP/DBP difference of $10 / 5 \mathrm{~mm} \mathrm{Hg}$. The column absolute risk reduction reports number and $95 \%$ confidence interval (Cl) of events prevented for every 1000 patients (pts) treated for 5 years with a standardized RR. CHD indicates coronary heart disease; CV, cardiovascular; and HF, heart failure (Data derived from Thomopoulos et $\mathrm{al}^{24}$ ). 


\section{Influence of Different Levels of Cardiovascular Risk on the Effects of BP-Lowering Treatment on Cardiovascular Outcomes}

An additional question of practical medical importance is whether the effects of BP-lowering treatment on fatal and nonfatal outcomes are similar or different at different levels of baseline cardiovascular risk and whether BP-lowering treatment should be preferentially addressed to patients in risk categories promising larger absolute treatment benefits. This question can hardly be approached within a single RCT, but it is particularly well suited to be addressed by meta-analysis of a large number of RCTs, each enrolling hypertensive patients at different cardiovascular risks.

In a recent set of meta-analyses, ${ }^{25}$ we have classified the 68 BP-lowering RCTs (245885 individuals) in 4 strata of increasing 10-year incidence of cardiovascular death in the control (placebo or less active treatment) group: (1) low-moderate risk $\left(<5 \%\right.$; $23 \mathrm{RCTs}^{30,32,44,46,57,58,60,64-68,71,74,76-78,81,82,87,89,91,95}$; 81675 individuals); (2) high risk ( $5 \%$ to $<10 \%$; $11 \mathrm{RCTs}^{28,35,37}$ (stratum 1),41,61,63,70,72,86,90,92; 46162 individuals); (3) very high risk

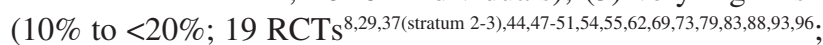
91152 individuals); (4) very very high risk ( $\geq 20 \%$; 16 $\operatorname{RCTs}^{9,31,33,34,39,40,42,45,52,53,56,59,85,87,94,95} ; 26881$ individuals). Relative reductions of all outcomes did not significantly differ in risk strata, but absolute risk reductions significantly increased with the increasing level of cardiovascular risk ( $P$ for trend always $<0.001$ except for CHD; Figure 7). For example, a SBP/DBP reduction of $10 / 5 \mathrm{~mm} \mathrm{Hg}$ reduced the incidence of major cardiovascular events (composite of stroke, CHD, and HF) by 7 (95\% confidence interval, 3-10), 32 (9-50), 56 (35-76), and 87 (52-112) events for every 1000 patients treated for 5 years, with numbers needed to treat for 5 years to prevent 1 event of 152 , 33,18 , and 11 , respectively. ${ }^{25}$

The influence of different levels of cardiovascular risk (calculated by a risk equation) on the relative and absolute risk reduction has recently been explored also by the BPLTTC in 11 RCTs of antihypertensive treatment (51917 individuals) in which individual data were available to the collaboration, ${ }^{115}$ with findings similar to ours, namely similar relative reduction and increasing absolute reductions of the incidence of major cardiovascular events with increasing baseline cardiovascular risk (the 11 RCTs could not provide sufficient statistical power for finding significant differences in specific outcome).

Both the BPLTTC meta-analysis ${ }^{115}$ and ours ${ }^{25}$ obviously suggest that the cost-effectiveness ratio of antihypertensive treatment becomes progressively more and more favorable the

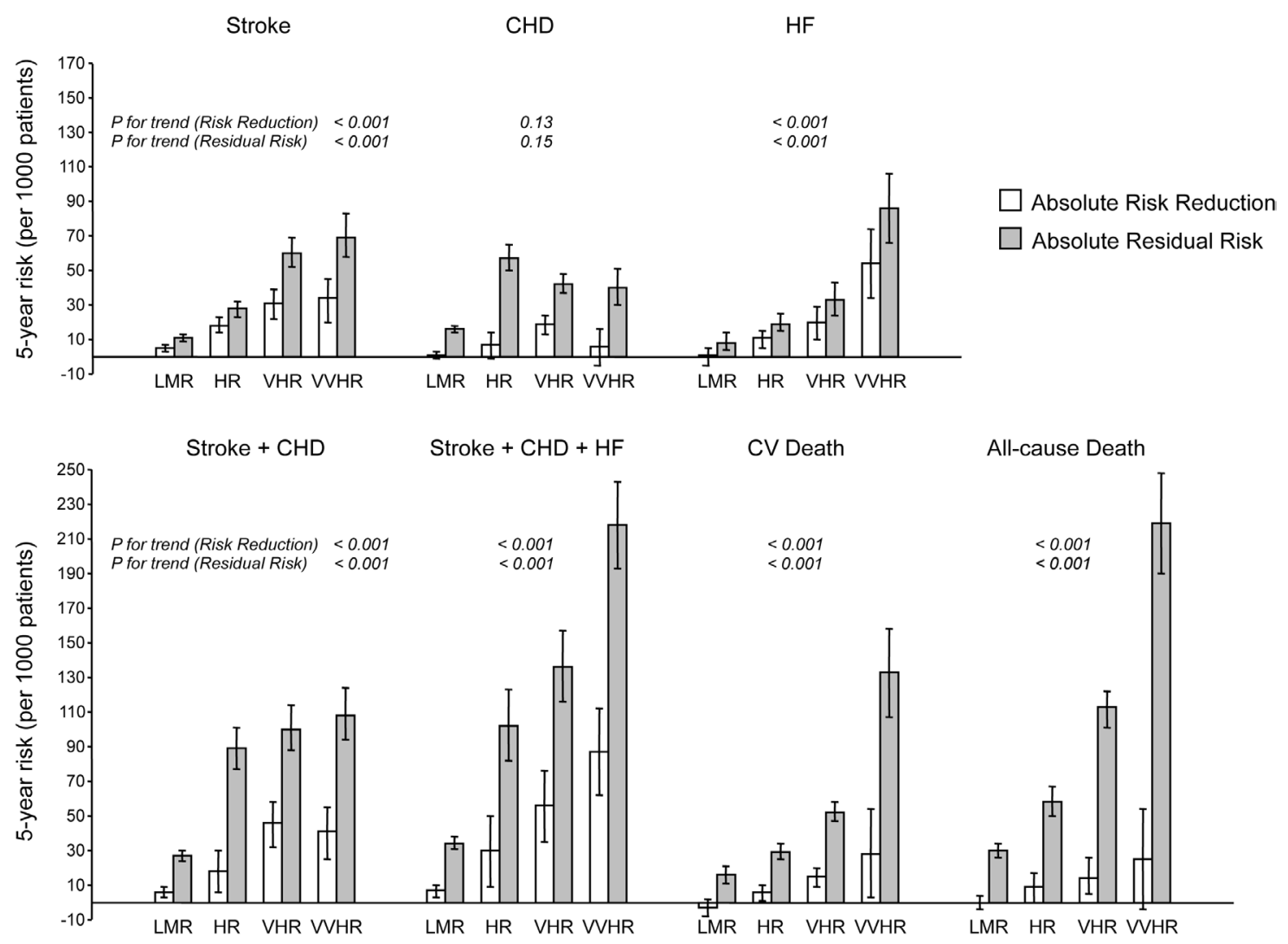

Figure 7. Absolute risk reduction by blood pressure (BP) lowering treatment (standardized to a SBP/DBP of $10 / 5 \mathrm{~mm} \mathrm{Hg}$ ) and residual risk in trials stratified by the increased level of cardiovascular (CV) risk in the control group. BP lowering produces greater absolute risk reduction (except for coronary heart disease [CHD]) the higher the level of CV risk, but a high level of risk is also associated with a higher absolute residual risk, measuring the failure of BP lowering. Absolute risk reductions (empty rectangles) and residual risk (shaded rectangles) are expressed as the number of events prevented or residual for every 1000 patients treated for 5 years. Vertical bars are $95 \%$ confidence intervals $(\mathrm{Cl})$. It is apparent that both benefits (risk reduction) and failures (residual risk) progressively increase with the increasing level of risk, but residual risk, particularly of mortality, increases more markedly. HF indicates heart failure; HR, high risk; LMR, low-moderate risk; VHR, very high risk; and VVHR, very very high risk (Reprinted from Thomopoulos et al ${ }^{25}$ with permission of the publisher. Copyright (C2014, Wolters Kluwer Health). 
higher the baseline risk of the patients being treated (in our meta-analysis, 11 rather than 152 patients to be treated for 5 years to prevent 1 major cardiovascular event). However, any enthusiasm for basing antihypertensive treatment decisions only on a risk-based approach, targeting those at the greatest cardiovascular risk, should be tempered by another important finding of our analyses. ${ }^{25}$ Figure 7 also shows that, notwithstanding the increasingly greater absolute risk reduction by BP lowering the higher was the baseline cardiovascular risk, the rates of all outcomes (CHD excluded) occurring in the actively or more actively treated groups of patients despite treatment (residual risk) remained progressively higher the higher the risk level in the control group. This means that, if the success of BP lowering is measured not only by the absolute reduction in outcome it achieves, but also by the absolute level of treatment failures (residual risk), ${ }^{116}$ it is undoubted that the greatest success of BP lowering is achieved in low-moderate risk patients, before some irreversible or scarcely reversible organ damage occurs.

There is another finding in our analyses that deserves some comment. CHD is the only outcome whose absolute reduction is not progressively greater higher is the risk of cardiovascular death, and whose residual risk does not increase with a progressive increase of cardiovascular death risk. ${ }^{25}$ Taken together with our observation that CHD events and all-cause death are the only outcomes whose reductions by BP lowering have not been found to be significantly proportional to the extent of BP lowering, ${ }^{23}$ these findings suggest that either CHD is less tightly associated with BP than other outcomes, such as stroke and $\mathrm{HF}$, or the benefits of $\mathrm{BP}$ lowering on $\mathrm{CHD}$ prevention may be partly balanced by untoward effects when cardiovascular risk is very high or when lower BP values are achieved.

\section{Conclusions}

A critical reappraisal of the morbidity and mortality effects shown by BP-lowering RCTs has been done first by establishing a precise definition of BP-lowering trials (trials comparing active treatment with placebo, no treatment or less active treatment, achieving a BP difference, performed in cohorts with $\geq 40 \%$ hypertensive patients, and exclusive of trials in acute myocardial infarction, HF, acute stroke, and dialysis). This has led to the identification of 68 RCTs, involving 245888 patients and 1058177 patient-years. Then, the results of these RCTs have been meta-analyzed grouping the RCTs on the basis of a series of clinically relevant questions, with the following conclusions:

1. All major types of cardiovascular events (stroke, CHD, $\mathrm{HF}$, and cardiovascular death) and death by any cause are significantly reduced by BP-lowering treatment, the effects being particularly large for stroke and HF. Absolute risk reductions are also substantial, amounting to the prevention of $\approx 29$ major cardiovascular events for every 1000 patients treated for 5 years.

2. Reductions of stroke, major cardiovascular events, and cardiovascular death are proportional to the reduction of SBP, DBP, and PP (with no closer relationship to any type of BP), but the logarithmic nature of the relationship implies that risk reduction increases to a progressively smaller extent the larger the BP reduction.
3. BP lowering by all classes of antihypertensive drugs is accompanied by significant reductions of stroke and major cardiovascular events. This supports the concept that reduction of these events is because of BP lowering per se. However, evidence of risk reduction of other cardiovascular events (CHD and HF) and, particularly, mortality has been found to date with some drug classes only. This cannot be taken to infer that some drug classes are inferior to others, unless differences between the effects of different drug classes are confirmed in RCTs with head-to-head comparison of the drugs.

4. Cardiovascular outcomes are significantly reduced in RCTs with average baseline SBP/DBP values within all grades (or stages) of hypertension, with no significant difference in relative risk reduction between different grades. Relative and absolute cardiovascular risks of most major outcomes are significantly reduced by BPlowering treatment also in predominantly grade 1 trials with low-moderate cardiovascular risk.

5. Lowering SBP to $<140 \mathrm{~mm} \mathrm{Hg}$ is able to reduce all types of cardiovascular outcomes (with the possible exception of HF) and cardiovascular and all-cause mortality. Lowering SBP to $<130 \mathrm{~mm} \mathrm{Hg}$ seems safe, but it only adds some further reduction in stroke to the benefits of lowering SBP to $<140 \mathrm{~mm} \mathrm{Hg}$.

6. BP-lowering treatment produces greater absolute risk reduction the higher the level of cardiovascular risk, but a higher level of risk is also associated with a higher absolute residual risk, measuring the failure of BP-lowering treatment. Targeting BP-lowering treatment to those with the greatest cardiovascular risk seems unwarranted because the reduction in the number of patients needing treatment to obtain a given benefit is counterbalanced by the dramatic increase in the number of patients in whom BP lowering fails to prevent fatal and nonfatal events.

On the whole, the conclusions of this reappraisal of BPlowering RCTs agree with the recommendations provided by some of the recent hypertension guidelines ${ }^{13,14,108}$ but give these recommendations a support stronger than that of experts' opinion.

\section{Acknowledgments}

We gratefully acknowledge the valuable help of Donatella Mihalich for literature searching and article preparation and that of Paulina Wijnmaalen for preparations of illustrations.

\section{Sources of Funding}

Financial support was made available to Istituto Auxologico Italiano by the Current Research Grants of the Ministry of Health of Italy, and in the context of contract EC 278249 (EU-MASCARA). C. Thomopoulos was a visiting investigator at the Istituto Auxologico Italiano, Milan, Italy, under a fellowship granted by the Hellenic Society of Cardiology.

\section{Disclosures}

A. Zanchetti declares lecture honoraria from Menarini International, Recordati SpA, and CVRx. C. Thomopoulos received consultancy fees from AstraZeneca and declares lecture honoraria from Sanofi. G. Parati declares lecture honoraria from Bayer, Daiichi Sankyo, Guidotti, and Boehringer Ingelheim. 


\section{References}

1. Zanchetti A. Evidence-based medicine in hypertension: what type of evidence? J Hypertens. 2005;23:1113-1120.

2. Zanchetti A. Interventional trials in hypertension: what have we learned and what remains to be learned? Manual of Hypertension of the European Society of Hypertension. 2nd ed. Boca Raton, CRC Press; 2014:Chapter 29, 283-298.

3. White P.D. Heart Disease. 3rd ed. New York: MacMillan; 1944.

4. Boerhaave H. Aphorismes, Amsterdam, 1709.

5. Evans W. Hypertonia or uneventful high blood pressure. Lancet. 1957;273:53-59.

6. Leishman AW. Hypertension: treated and untreated; a study of 400 cases. Br Med J. 1959;1:1361-1368.

7. Hamilton M, Thompson EM, Wisniewski TK. The role of bloodpressure control in preventing complications of hypertension. Lancet. 1964;1:235-238.

8. Wolff FW, Lindeman RD. Effects of treatment in hypertension: results of a controlled study. J Chronic Dis. 1966;19:227-240.

9. Veterans Administration Cooperative Study Group on Antihypertensive Agents. Effects of treatment on morbidity in hypertension: results in patients with diastolic blood pressure averaging 115 through $129 \mathrm{mmHg}$. JAMA 1967; 202:1028-1034.

10. Collins R, MacMahon S. Blood pressure, antihypertensive drug treatment and the risks of stroke and of coronary heart disease. $\mathrm{Br}$ Med Bull. 1994;50:272-298.

11. Zanchetti A, Grassi G, Mancia G. When should antihypertensive drug treatment be initiated and to what levels should systolic blood pressure be lowered? A critical reappraisal. J Hypertens. 2009;27:923-934. doi: 10.1097/HJH.0b013e32832aa6b5.

12. Mancia G, Laurent S, Agabiti-Rosei E, et al; European Society of Hypertension. Reappraisal of European guidelines on hypertension management: a European Society of Hypertension Task Force document. J Hypertens. 2009;27:2121-2158. doi: 10.1097/ HJH.0b013e328333146d.

13. Mancia G, Fagard R, Narkiewicz K, et al; Task Force Members. 2013 ESH/ESC Guidelines for the management of arterial hypertension: the Task Force for the management of arterial hypertension of the European Society of Hypertension (ESH) and of the European Society of Cardiology (ESC). J Hypertens. 2013;31:1281-1357. doi: 10.1097/01. hjh.0000431740.32696.cc.

14. James PA, Oparil S, Carter BL, et al. 2014 evidence-based guideline for the management of high blood pressure in adults: report from the panel members appointed to the Eighth Joint National Committee (JNC 8). JAMA. 2014;311:507-520. doi: 10.1001/jama.2013.284427.

15. Collins R, Peto R, MacMahon S, Godwin J, Qizilbash N, Hebert P, Eberlein KA, Taylor JP, Hennekens CH, Fiebacj NH, Qizilbash N, Hennekens CH. Blood pressure, stroke, and coronary heart disease. Part 2, short-term reductions in blood pressure: overview of randomised drug trials in their epidemiological context. Lancet. 1990;335:827-839.

16. Blood Pressure Lowering Treatment Trialists' Collaboration. Effects of ACE inhibitors, calcium antagonists, and other blood-pressure-lowering drugs: results of prospectively designed overviews of randomised trials. Lancet. 2000;356:1955-1964

17. Blood Pressure Lowering Treatment Trialists' Collaboration. Effects of different blood-pressure-lowering regimens on major cardiovascular events: results of prospectively designed overviews of randomised trials. Lancet. 2003;362:1527-1535.

18. Blood Pressure Lowering Treatment Trialists' Collaboration. Effects of different blood pressure-lowering regimens on major cardiovascular events in individuals with and without diabetes mellitus: results of prospectively designed overviews of randomized trials. Arch Intern Med. 2005;165:1410-1419.

19. World Health Organization-International Society of Hypertension Blood Pressure Lowering Treatment Trialists' Collaboration. Protocol for prospective collaborative overviews of major randomized trials of bloodpressure lowering treatments. J Hypertens. 1998;16:127-137.

20. Law MR, Morris JK, Wald NJ. Use of blood pressure lowering drugs in the prevention of cardiovascular disease: meta-analysis of 147 randomised trials in the context of expectations from prospective epidemiological studies. Br Med J. 2009;338:b1665

21. Bangalore S, Messerli FH. Commentary: counterpoint. Simpleminded antihypertensive treatment: of assumptions, potpourri, and sausages. J Clin Hypertens (Greenwich). 2009;11:702-706. doi: 10.1111/j.1751-7176.2009.00203.x.
22. Zanchetti A. Hypertension: meta-analyses: first-rank evidence or second-hand information? Nat Rev Cardiol. 2011;8:249-251. doi: 10.1038/ nrcardio.2011.39.

23. Thomopoulos C, Parati G, Zanchetti A. Effects of blood pressure lowering on outcome incidence in hypertension: 1. overview, meta-analyses, and meta-regression analyses of randomized trials. J Hypertens. 2014;32:2285-2295. doi: 10.1097/HJH.0000000000000378.

24. Thomopoulos C, Parati G, Zanchetti A. Effects of blood pressure lowering on outcome incidence in hypertension: 2. effects at different baseline and achieved blood pressure levels-overview and meta-analyses of randomized trials. J Hypertens. 2014;32:2296-2304. doi: 10.1097/ HJH.0000000000000379.

25. Thomopoulos C, Parati G, Zanchetti A. Effects of blood pressure lowering on outcome incidence in hypertension: 3. effects in patients at different levels of cardiovascular risk-overview and meta-analyses of randomized trials. J Hypertens. 2014;32:2305-2314. doi: 10.1097/ HJH.0000000000000380.

26. Thomopoulos C, Parati G, Zanchetti A. Effects of blood pressure lowering on outcome incidence in hypertension: 4. effects of various classes of antihypertensive drugs-overview and meta-analyses. J Hypertens. 2015;33:195-211. doi: 10.1097/HJH.0000000000000447.

27. Moher D, Liberati A, Tetzlaff J, Altman DG; PRISMA Group. Preferred reporting items for systematic reviews and meta-analyses: the PRISMA statement. Br Med J. 2009;339:b2535.

28. Poole-Wilson PA, Lubsen J, Kirwan BA, et al; A Coronary disease Trial Investigating Outcome with Nifedipine gastrointestinal therapeutic system investigators. Effect of long-acting nifedipine on mortality and cardiovascular morbidity in patients with stable angina requiring treatment (ACTION trial): randomised controlled trial. Lancet. 2004;364:849-857. doi: 10.1016/S0140-6736(04)16980-8.

29. ADVANCE Collaborative Group. Effects of a fixed combination of perindopril and indapamide on macrovascular and microvascular outcomes in patients with type 2 diabetes mellitus (the ADVANCE trial): a randomised controlled trial. Lancet. 2007;37:829-840.

30. Management Committee. The Australian therapeutic trial in mild hypertension. Lancet. 1980;315:1261-1267.

31. Barraclough M, Bainton D, Cochrane AL. Control of moderately raised blood pressure. Report of a co-operative randomized controlled trial. $\mathrm{Br}$ Med J 1973;3:434-436.

32. Nissen SE, Tuzcu EM, Libby P, Thompson PD, Ghali M, Garza D, Berman L, Shi H, Buebendorf E, Topol EJ; CAMELOT Investigators. Effect of antihypertensive agents on cardiovascular events in patients with coronary disease and normal blood pressure: the CAMELOT study: a randomized controlled trial. JAMA. 2004;292:2217-2225. doi: 10.1001/jama.292.18.2217.

33. Carter BA. Hypotensive therapy in stroke survivors. Lancet. 1970;295:485-489.

34. Amery A, Brixko P, Clement D, et al. Mortality and morbidity results from the European Working Party on High Blood Pressure in the Elderly trial. Lancet. 1985;325:1349-1354.

35. Liu L, Zhang Y, Liu G, Li W, Zhang X, Zanchetti A; FEVER Study Group. The Felodipine Event Reduction (FEVER) Study: a randomized long-term placebo-controlled trial in Chinese hypertensive patients. J Hypertens. 2005;23:2157-2172.

36. Zhang Y, Zhang X, Liu L, Zanchetti A; FEVER Study Group. Is a systolic blood pressure target $<140 \mathrm{mmHg}$ indicated in all hypertensives? Subgroup analyses of findings from the randomized FEVER trial. Eur Heart J. 2011;32:1500-1508. doi: 10.1093/eurheartj/ehr039.

37. Hypertension Detection and Follow-up Program Cooperative Group. Five-year findings of the Hypertension Detection and Follow-up Program. I. Reduction in mortality of persons with high blood pressure, including mild hypertension. JAMA. 1979;242:2562-2571.

38. Davis BR, Ford CE. The Hypertension Detection Follow-up Program. In: Black HR, ed. Clinical Trials in Hypertension. New York: Marcel Dekker, Inc; Chapter 3, 2001:27-60.

39. Coope J, Warrender TS. Randomised trial of treatment of hypertension in elderly patients in primary care. Br Med J (Clin Res Ed). 1986;293:1145-1151.

40. Hypertension-Stroke Cooperative Study Group. Effect of antihypertensive treatment on stroke recurrence. JAMA. 1974;229:409-418.

41. Sun M, Zhou H, Jia Z. Prevention and treatment of stroke after hypertension for ten years in Hunan Province. Zhonghua Nei Ke Za Zhi. 1997;36:312-314.

42. Bulpitt CJ, Beckett NS, Cooke J, Dumitrascu DL, Gil-Extremera B, Nachev C, Nunes M, Peters R, Staessen JA, Thijs L; Hypertension in the Very Elderly Trial Working Group. Results of the pilot study for the 
hypertension in the very elderly trial. $J$ Hypertens. 2003;21:2409-2417. doi: 10.1097/01.hjh.0000084782.15238.a2.

43. Beckett NS, Peters R, Fletcher AE, et al; HYVET Study Group. Treatment of hypertension in patients 80 years of age or older. $N$ Engl $\mathrm{J} \mathrm{Med}$. 2008;358:1887-1898. doi: 10.1056/NEJMoa0801369.

44. Medical Research Council Working Party. MRC trial on treatment of mild hypertension: principal results. Br Med J. 1985;291:97-104.

45. MRC Working Party. Medical Research Council trial of treatment of hypertension in older adults: principal results. $\mathrm{Br}$ Med $\mathrm{J}$ 1992;304:405-412.

46. Helgeland A. Treatment of mild hypertension: a five year controlled drug trial. The Oslo study. Am J Med. 1980;69:725-732.

47. PATS Collaborating Group. Poststroke antihypertensive treatment study. A preliminary result. Chin Med J (Engl). 1995;108:710-717.

48. PROGRESS Collaborative Group. Randomised trial of a perindopril based blood-pressure-lowering regimen among 6105 individuals with previous stroke or transient ischaemic attack. Lancet. 2001;358:1033-1041.

49. Lithell H, Hansson L, Skoog I, Elmfeldt D, Hofman A, Olofsson B, Trenkwalder P, Zanchetti A; SCOPE Study Group. The Study on Cognition and Prognosis in the Elderly (SCOPE): principal results of a randomized double-blind intervention trial. J Hypertens. 2003;21:875-886. doi: 10.1097/01.hjh.0000059028.82022.89.

50. Perry HM Jr, Smith WM, McDonald RH, Black D, Cutler JA, Furberg CD, Greenlick MR, Kuller LH, Schnaper HW, Schoenberger JA. Morbidity and mortality in the Systolic Hypertension in the Elderly Program (SHEP) pilot study. Stroke. 1989;20:4-13.

51. SHEP Co-operative Research Group. Prevention of stroke by antihypertensive drug treatment in older persons with isolated systolic hypertension. Final results of the Systolic Hypertension in the Elderly Program (SHEP). JAMA. 1991;265:3255-3264.

52. Sprackling ME, Mitchell JR, Short AH, Watt G. Blood pressure reduction in elderly: a randomised controlled trial of methyldopa. $\mathrm{Br} \mathrm{Med} \mathrm{J} \mathrm{(Clin}$ Res $E d)$. 1981;283:1151-1153.

53. Dahlöf B, Lindholm LH, Hansson L, Scherstén B, Ekbom T, Wester PO. Morbidity and mortality in the Swedish Trial in Old Patients with Hypertension (STOP-Hypertension). Lancet. 1991;338:1281-1285.

54. Liu L, Wang JG, Gong L, Liu G, Staessen JA; Systolic Hypertension in China (Syst-China) Collaborative Group. Comparison of active treatment and placebo in older Chinese patients with isolated systolic hypertension. J Hypertens. 1998;16:1823-1829.

55. Staessen JA, Fagard R, Thijs L, et al. Randomised double-blind comparison of placebo and active treatment for older patients with isolated systolic hypertension. The Systolic Hypertension in Europe (Syst-Eur) Trial Investigators. Lancet. 1997;350:757-764.

56. Eriksson S, Olofsson B-O, Wester P-O; the TEST (Tenormin after Stroke and TIA) study group. Atenolol in secondary prevention after stroke. Cerebrovasc Dis. 1995;5:21-25.

57. Neaton JD, Grimm RH Jr, Prineas RJ, Stamler J, Grandits GA, Elmer PJ, Cutler JA, Flack JM, Schoenberger JA, McDonald R; Treatment of Mild Hypertension Study Research Group. Treatment of Mild Hypertension Study: final results. JAMA. 1993;270:713-724.

58. Smith WM. Treatment of mild hypertension: results of a ten-year intervention trial. Circ Res. 1977;40:198-105.

59. Veterans Administration Cooperative Study Group on Antihypertensive Agents. Effects of treatment on morbidity in hypertension: results in patients with diastolic blood pressures averaging 90 through $114 \mathrm{mmHg}$. JAMA. 1970;213:1143-1152.

60. Perry HM Jr, Goldman AI, Lavin MA, Schnaper HW, Fitz AE, Frohlich ED, Steele B, Richman HG. Evaluation of drug treatment in mild hypertension: VA-NHLBI feasibility trial. Plan and preliminary results of a twoyear feasibility trial for a multicenter intervention study to evaluate the benefits versus the disadvantages of treating mild hypertension. Prepared for the Veterans Administration-National Heart, Lung, and Blood Institute Study Group for Evaluating Treatment in Mild Hypertension. Ann N Y Acad Sci. 1978;304:267-292.

61. Wright JT Jr, Bakris G, Greene T, et al; African American Study of Kidney Disease and Hypertension Study Group. Effect of blood pressure lowering and antihypertensive drug class on progression of hypertensive kidney disease: results from the AASK trial. JAMA. 2002;288:2421-2431.

62. Estacio RO, Jeffers BW, Gifford N, Schrier RW. Effect of blood pressure control on diabetic microvascular complications in patients with hypertension and type 2 diabetes. Diabetes Care. 2000;23(suppl 2):B54-B64.

63. The ACCORD Study Group. Effects of intensive blood-pressure control in type 2 diabetes mellitus. N Engl J Med. 2010;362:1575-1585.
64. Hansson L. The BBB Study: the effect of intensified antihypertensive treatment on the level of blood pressure, side-effects, morbidity and mortality in "well-treated" hypertensive patients. Behandla Blodtryck Bättre. Blood Press. 1994;3:248-254.

65. Verdecchia P, Staessen JA, Angeli F, de Simone G, Achilli A, Ganau A, Mureddu G, Pede S, Maggioni AP, Lucci D, Reboldi G; Cardio-Sis Investigators. Usual versus tight control of systolic blood pressure in nondiabetic patients with hypertension (Cardio-Sis): an open-label randomised trial. Lancet. 2009;374:525-533. doi: 10.1016/S0140-6736(09)61340-4.

66. Fogari R, Preti P, Zoppi A, Rinaldi A, Corradi L, Pasotti C, Poletti L, Marasi G, Derosa G, Mugellini A, Voglini C, Lazzari P. Effects of amlodipine fosinopril combination on microalbuminuria in hypertensive type 2 diabetic patients. Am J Hypertens. 2002;15:1042-1049.

67. Hansson L, Zanchetti A, Carruthers SG, Dahlöf B, Elmfeldt D, Julius S, Ménard J, Rahn KH, Wedel H, Westerling S. Effects of intensive bloodpressure lowering and low-dose aspirin in patients with hypertension: principal results of the Hypertension Optimal Treatment (HOT) randomised trial. HOT Study Group. Lancet. 1998;351:1755-1762.

68. JATOS Study Group. Principal results of the Japanese Trial to assess Optimal Systolic blood pressure in elderly hypertensive patients (JATOS). Hypertens Res. 2008;31:2115-2127.

69. Lazarus JM, Bourgoignie JJ, Buckalew VM, Greene T, Levey AS, Milas NC, Paranandi L, Peterson JC, Porush JG, Rauch S, Soucie JM, Stollar C. Achievement and safety of a low blood pressure goal in chronic renal disease. The Modification of Diet in Renal Disease Study Group. Hypertension. 1997;29:641-650.

70. Ruggenenti P, Perna A, Loriga G, et al; REIN-2 Study Group. Bloodpressure control for renoprotection in patients with non-diabetic chronic renal disease (REIN-2): multicentre, randomised controlled trial. Lancet. 2005;365:939-946. doi: 10.1016/S0140-6736(05)71082-5.

71. Howard BV, Roman MJ, Devereux RB, et al. Effect of lower targets for blood pressure and LDL cholesterol on atherosclerosis in diabetes: the SANDS randomized trial. JAMA. 2008;299:1678-1689. doi: 10.1001/ jama.299.14.1678.

72. Benavente OR, Coffey CS, Conwit R, Hart RG, McClure LA, Pearce LA, Pergola PE, Szychowski JM; SPS3 Study Group. Blood-pressure targets in patients with recent lacunar stroke: the SPS3 randomised trial. Lancet. 2013;382:507-515. doi: 10.1016/S0140-6736(13)60852-1.

73. UK Prospective Diabetes Study Group. Tight blood pressure control and risk of macrovascular and microvascular complications in type 2 diabetes: UKPDS 38. Br Med J. 1998;317:703-713.

74. Ogihara T, Saruta T, Rakugi H, Matsuoka H, Shimamoto K, Shimada K, Imai Y, Kikuchi K, Ito S, Eto T, Kimura G, Imaizumi T, Takishita $\mathrm{S}$, Ueshima H; Valsartan in Elderly Isolated Systolic Hypertension Study Group. Target blood pressure for treatment of isolated systolic hypertension in the elderly: valsartan in elderly isolated systolic hypertension study. Hypertension. 2010;56:196-202. doi: 10.1161/ HYPERTENSIONAHA.109.146035.

75. The ACTIVE I Investigators. Irbesartan in patients with atrial fibrillation. N Engl J Med. 2011;364:928-938.

76. Maschio G, Alberti D, Janin G, Locatelli F, Mann JF, Motolese M, Ponticelli C, Ritz E, Zucchelli P; The Angiotensin-Converting-Enzyme Inhibition in Progressive Renal Insufficiency Study Group. Effect of the angiotensin-converting-enzyme inhibitor benazepril on the progression of chronic renal insufficiency. N Engl J Med. 1996;334:939-945. doi: 10.1056/NEJM199604113341502.

77. Ruggenenti P, Fassi A, Ilieva AP, et al; Bergamo Nephrologic Diabetes Complications Trial (BENEDICT) Investigators. Preventing microalbuminuria in type 2 diabetes. $N$ Engl J Med. 2004;351:1941-1951. doi: 10.1056/NEJMoa042167.

78. Ruggenenti P, Lauria G, Iliev IP, et al; the DEMAND study Investigators. Effects of manidipine and delapril in hypertensive patients with type 2 diabetes mellitus: The Delapril and Manidipine for Nephroprotection in Diabetes (DEMAND) randomized clinical trial. Hypertension. 2011;58:776-783.

79. Marre M, Lievre M, Chatellier G, Mann JF, Passa P, Ménard J; DIABHYCAR Study Investigators. Effects of low dose ramipril on cardiovascular and renal outcomes in patients with type 2 diabetes and raised excretion of urinary albumin: randomised, double blind, placebo controlled trial (the DIABHYCAR study). Br Med J. 2004;328:495. doi: 10.1136/ bmj.37970.629537.0D.

80. Sjølie AK, Klein R, Porta M, Orchard T, Fuller J, Parving HH, Bilous R, Chaturvedi N; DIRECT Programme Study Group. Effect of candesartan on progression and regression of retinopathy in type 2 
diabetes (DIRECT-Protect 2): a randomised placebo-controlled trial. Lancet. 2008;372:1385-1393. doi: 10.1016/S0140-6736(08)61411-7.

81. DREAM Trial Investigators. Effects of ramipril and rosiglitazone on cardiovascular and renal outcomes in people with impaired glucose tolerance or impaired fasting glucose: results of the Diabetes REduction Assessment with ramipril and rosiglitazone Medication (DREAM) trial. Diabetes Care. 2008;31:1007-1014.

82. The GISSI-AF Investigators. Valsartan for prevention of recurrent atrial fibrillation. N Engl J Med. 2009;360:1606-1617.

83. The Heart Outcomes Prevention Evaluation Study Investigators. Effects of an angiotensin-converting-enzyme inhibitor, ramipril, on cardiovascular events in high-risk patients. $N$ Engl J Med. 2000;342:145-153.

84. Heart Outcomes Prevention Evaluation Study Investigators. Effects of ramipril on cardiovascular and microvascular outcomes in people with diabetes mellitus: results of the HOPE study and MICRO-HOPE sub-study. Lancet. 2000;355:253-259.

85. Lewis EJ, Hunsicker LG, Clarke WR, Berl T, Pohl MA, Lewis JB, Ritz E, Atkins RC, Rohde R, Raz I; Collaborative Study Group. Renoprotective effect of the angiotensin-receptor antagonist irbesartan in patients with nephropathy due to type 2 diabetes. $N$ Engl J Med. 2001;345:851-860. doi: 10.1056/NEJMoa011303.

86. Parving HH, Lehnert H, Bröchner-Mortensen J, Gomis R, Andersen S, Arner P; Irbesartan in Patients with Type 2 Diabetes and Microalbuminuria Study Group. The effect of irbesartan on the development of diabetic nephropathy in patients with type 2 diabetes. N Engl J Med. 2001;345:870878. doi: 10.1056/NEJMoa011489.

87. Massie BM, Carson PE, McMurray JJ, Komajda M, McKelvie R, Zile MR, Anderson S, Donovan M, Iverson E, Staiger C, Ptaszynska A; I-PRESERVE Investigators. Irbesartan in patients with heart failure and preserved ejection fraction. $N$ Engl J Med. 2008;359:2456-2467. doi: 10.1056/NEJMoa0805450.

88. Lewis EJ, Hunsicker LG, Bain RP, Rohde RD; The Collaborative Study Group. The effect of angiotensin-converting-enzyme inhibition on diabetic nephropathy. N Engl J Med. 1993;329:1456-1462. doi: 10.1056/ NEJM199311113292004.

89. The NAVIGATOR study Group. Effect of valsartan on the incidence of diabetes and cardiovascular events. N Eng J Med. 2010;362:1477-1490.

90. Dens JA, Desmet WJ, Coussement P, De Scheerder IK, Kostopoulos K, Kerdsinchai P, Supanantaroek C, Piessens JH. Long term effects of nisoldipine on the progression of coronary atherosclerosis and the occurrence of clinical events: the NICOLE study. Heart. 2003;89:887-892.

91. Imai E, Chan JC, Ito S, Yamasaki T, Kobayashi F, Haneda M, Makino H; ORIENT Study Investigators. Effects of olmesartan on renal and cardiovascular outcomes in type 2 diabetes with overt nephropathy: a multicentre, randomised, placebo-controlled study. Diabetologia. 2011;54:2978-2986. doi: 10.1007/s00125-011-2325-z.

92. The PEACE Trial Investigators. Angiotensin-converting-enzyme inhibition in stable coronary artery disease. N Engl J Med. 2004;351:2058-2068.

93. Yusuf S, Diener HC, Sacco RL, et al; PRoFESS Study Group. Telmisartan to prevent recurrent stroke and cardiovascular events. $N$ Engl J Med. 2008;359:1225-1237. doi: 10.1056/NEJMoa0804593.

94. Brenner BM, Cooper ME, de Zeeuw D, Keane WF, Mitch WE, Parving HH, Remuzzi G, Snapinn SM, Zhang Z, Shahinfar S; RENAAL Study Investigators. Effects of losartan on renal and cardiovascular outcomes in patients with type 2 diabetes and nephropathy. $N$ Engl J Med. 2001;345:861-869. doi: 10.1056/NEJMoa011161.

95. Haller H, Ito S, Izzo JL Jr, Januszewicz A, Katayama S, Menne J, Mimran A, Rabelink TJ, Ritz E, Ruilope LM, Rump LC, Viberti G; ROADMAP Trial Investigators. Olmesartan for the delay or prevention of microalbuminuria in type 2 diabetes. $N$ Engl J Med. 2011;364:907-917. doi: 10.1056/NEJMoa1007994.

96. Telmisartan Randomized Assessment Study in ACE intolerant subjects with cardiovascular disease (TRANSCEND) Investigators. Effects of the angiotensin-receptor blocker telmisartan on cardiovascular events in highrisk patients intolerant to angiotensin-converting enzyme inhibitors: a randomised controlled trial. Lancet. 2008;372:1174-1183.

97. Lewington S, Clarke R, Qizilbash N, Peto R, Collins R; Prospective Studies Collaboration. Age-specific relevance of usual blood pressure to vascular mortality: a meta-analysis of individual data for one million adults in 61 prospective studies. Lancet. 2002;360:1903-1913.

98. Lindholm LH, Carlberg B, Samuelsson O. Should beta blockers remain first choice in the treatment of primary hypertension? A meta-analysis. Lancet. 2005;366:1545-1553. doi: 10.1016/S0140-6736(05)67573-3.
99. Reboldi G, Gentile G, Angeli F, Ambrosio G, Mancia G, Verdecchia P. Effects of intensive blood pressure reduction on myocardial infarction and stroke in diabetes: a meta-analysis in 73913 patients. J Hypertens. 2011;29:1253-1269. doi: 10.1097/HJH.0b013e3283469976.

100. Verdecchia P, Reboldi G, Angeli F, Gattobigio R, Bentivoglio M, Thijs L, Staessen JA, Porcellati C. Angiotensin-converting enzyme inhibitors and calcium channel blockers for coronary heart disease and stroke prevention. Hypertension. 2005;46:386-392. doi: 10.1161/01. HYP.0000174591.42889.a2.

101. Costanzo P, Perrone-Filardi P, Petretta M, Marciano C, Vassallo E, Gargiulo P, Paolillo S, Petretta A, Chiariello M. Calcium channel blockers and cardiovascular outcomes: a meta-analysis of 175,634 patients. JHypertens. 2009;27:1136-1151.doi: 10.1097/HJH.0b013e3283281254.

102. Wright JM, Musini VM. First-line drugs for hypertension. Cochrane Database Syst Rev. 2009;3:CD001841. doi: 10.1002/14651858. CD001841.pub2.

103. Bangalore S, Kumar S, Wetterslev J, Messerli FH. Angiotensin receptor blockers and risk of myocardial infarction: meta-analyses and trial sequential analyses of 147020 patients from randomised trials. BMJ. 2011;342:d2234.

104. van Vark LC, Bertrand M, Akkerhuis KM, Brugts JJ, Fox K, Mourad JJ, Boersma E. Angiotensin-converting enzyme inhibitors reduce mortality in hypertension: a meta-analysis of randomized clinical trials of reninangiotensin-aldosterone system inhibitors involving 158998 patients. Eur Heart J. 2012;33:2088-2097. doi: 10.1093/eurheartj/ehs075.

105. Wiysonge CS, Bradley HA, Volmink J, Mayosi BM, Mbewu A, Opie LH. Beta-blockers of hypertension. Cochrane Database Syst Rev. 2012;11:CD002003. doi: 10.1002/14651858.CD002003.pub4.

106. Savarese G, Costanzo P, Cleland JG, Vassallo E, Ruggiero D, Rosano G, Perrone-Filardi P. A meta-analysis reporting effects of angiotensinconverting enzyme inhibitors and angiotensin receptor blockers in patients without heart failure. J Am Coll Cardiol. 2013;61:131-142. doi: 10.1016/j.jacc.2012.10.011.

107. Chobanian AV, Bakris GL, Black HR, Cushman WC, Green LA, Izzo JL Jr, Jones DW, Materson BJ, Oparil S, Wright JT Jr, Roccella EJ; Joint National Committee on Prevention, Detection, Evaluation, and Treatment of High Blood Pressure; National Heart, Lung, and Blood Institute; National High Blood Pressure Education Program Coordinating Committee. Seventh report of the Joint National Committee on Prevention, Detection, Evaluation, and Treatment of High Blood Pressure. Hypertension. 2003;42: 1206-1252. doi: 10.1161/01.HYP.0000107251.49515.c2.

108. Weber MA, Schiffrin EL, White WB, et al. Clinical practice guidelines for the management of hypertension in the community a statement by the American Society of Hypertension and the International Society of Hypertension. J Hypertens. 2014;32:3-15. doi: 10.1097/HJH.0000000000000065.

109. National Institute for Health and Clinical Excellence. Hypertension (CG127): clinical management of primary hypertension in adults. http:// www.nice.org.uk/guidance/CG127.

110. Diao D, Wright JM, Cundiff DK, Gueyffier F. Pharmacotherapy for mild hypertension. Cochrane Database Syst Rev. 2012;8:CD006742. doi: 10.1002/14651858.CD006742.pub2.

111. Czernichow S, Zanchetti A, Turnbull F, et al; Blood Pressure Lowering Treatment Trialists' Collaboration. The effects of blood pressure reduction and of different blood pressure-lowering regimens on major cardiovascular events according to baseline blood pressure: meta-analysis of randomized trials. J Hypertens. 2011;29:4-16.

112. Thompson AM, Hu T, Eshelbrenner CL, Reynolds K, He J, Bazzano LA. Antihypertensive treatment and secondary prevention of cardiovascular disease events among persons without hypertension: a meta-analysis. JAMA. 2011;305:913-922. doi: 10.1001/jama.2011.250.

113. Sundström J, Arima H, Jackson R, Turnbull F, Rahimi K, Chalmers J, Woodward M, Neal B; on behalf of the Blood Pressure Lowering Treatment Trialists' Collaboration. Effects of blood pressure reduction in mild hypertension: systematic review and meta-analysis. Ann Intern Med. 2015;162(3):184-191.

114. Zanchetti A, Liu L, Mancia G, et al. Blood pressure and low-density lipoprotein-cholesterol lowering for prevention of strokes and cognitive decline: a review of available trial evidence. J Hypertens. 2014;32: 1741-1750. doi: 10.1097/HJH.0000000000000253.

115. Blood Pressure Lowering Treatment Trialists' Collaboration. Predicted cardiovascular risk can inform decisions to lower blood pressure with drugs: evidence from an individual patient data meta-analysis. Lancet. 2014;384:591-598.

116. Zanchetti A. Bottom blood pressure or bottom cardiovascular risk? How far can cardiovascular risk be reduced? J Hypertens. 2009;27: 1509-1520. doi: 10.1097/HJH.0b013e32832e9500. 


\title{
Circulation Research
}

\section{Randomized Controlled Trials of Blood Pressure Lowering in Hypertension: A Critical Reappraisal \\ Alberto Zanchetti, Costas Thomopoulos and Gianfranco Parati}

Circ Res. 2015;116:1058-1073

doi: 10.1161/CIRCRESAHA.116.303641

Circulation Research is published by the American Heart Association, 7272 Greenville Avenue, Dallas, TX 75231 Copyright (C) 2015 American Heart Association, Inc. All rights reserved.

Print ISSN: 0009-7330. Online ISSN: 1524-4571

The online version of this article, along with updated information and services, is located on the World Wide Web at:

http://circres.ahajournals.org/content/116/6/1058

\begin{abstract}
Permissions: Requests for permissions to reproduce figures, tables, or portions of articles originally published in Circulation Research can be obtained via RightsLink, a service of the Copyright Clearance Center, not the Editorial Office. Once the online version of the published article for which permission is being requested is located, click Request Permissions in the middle column of the Web page under Services. Further information about this process is available in the Permissions and Rights Question and Answer document.
\end{abstract}

Reprints: Information about reprints can be found online at: http://www.lww.com/reprints

Subscriptions: Information about subscribing to Circulation Research is online at: http://circres.ahajournals.org//subscriptions/ 